University of Texas Rio Grande Valley

ScholarWorks @ UTRGV

Mechanical Engineering Faculty Publications and Presentations

$12-2019$

\title{
Energy and exergy analysis of a novel multiple-effect vapor chamber distillation system for high-salinity wastewater treatment
}

\author{
Hamidreza Shabgard \\ University of Oklahoma \\ Ramkumar Parthasarathy \\ University of Oklahoma \\ Ben Xu \\ The University of Texas Rio Grande Valley, ben.xu@utrgv.edu
}

Follow this and additional works at: https://scholarworks.utrgv.edu/me_fac

Part of the Mechanical Engineering Commons, and the Water Resource Management Commons

\section{Recommended Citation}

Shabgard, H., Parthasarathy, R., \& Xu, B. (2019). Energy and exergy analysis of a novel multiple-effect vapor chamber distillation system for high-salinity wastewater treatment. Desalination and Water Treatment, 171, 1-17. https://doi.org/10.5004/dwt.2019.25017

This Article is brought to you for free and open access by the College of Engineering and Computer Science at ScholarWorks@ UTRGV. It has been accepted for inclusion in Mechanical Engineering Faculty Publications and Presentations by an authorized administrator of ScholarWorks @ UTRGV. For more information, please contact justin.white@utrgv.edu,william.flores01@utrgv.edu. 


\title{
Energy and exergy analysis of a novel multiple-effect vapor chamber distillation system for high-salinity wastewater treatment
}

\author{
Hamidreza Shabgard ${ }^{\mathrm{a}, *}$, Ramkumar Parthasarathy ${ }^{\mathrm{a}}$, Ben $\mathrm{Xu}^{\mathrm{b}}$ \\ ${ }^{a}$ School of Aerospace and Mechanical Engineering, University of Oklahoma, 865 Asp Ave., Norman, OK 73019, USA, \\ Tel.+1-405-325-5753; email: shabgard@ou.edu (H. Shabgard), Tel.+1-405-325-1735; email: rparthasarathy@ou.edu (R. Parthasarathy) \\ ${ }^{b}$ Department of Mechanical Engineering, The University of Texas Rio Grande Valley, Edinburg, TX 78539, USA, \\ Tel.+1-956-665-2896; email: ben.xu@utrgv.edu
}

Received 1 May 2019; Accepted 8 October 2019

\begin{abstract}
A B S T R A C T
A novel modular thermally-driven multiple-effect vapor chamber distillation (MVCD) system is presented for compact and portable desalination applications. The MVCD system consists of several vapor chambers connected in series with the condenser section of the upstream vapor chambers serving as the evaporator section of the following effect. A heat transfer model accounting for the major thermal resistances was developed to predict the heat transfer and distilled water production rates. A mass transfer analysis was performed to evaluate the effect of the accumulation of the non-condensable gasses within the chambers. An exergy analysis was also conducted to quantify the efficiency of the system from the viewpoint of the second law of thermodynamics. It was found that for a fixed number of effects, increasing the hot-end temperature increased the distillation rate and decreased the second law efficiency. On the other hand, increasing the number of effects at a fixed hot-end temperature resulted in increased distillation rate and second law efficiency. The increased salinity of the feed water resulted in smaller distillation rates and greater second law efficiency. For all the cases, it was found that sensible heat recovery from the discharging fluids could improve the gained output ratio (GOR) and the second law efficiency by about $10 \%$. Quantitatively, at a hot-end temperature of $70^{\circ} \mathrm{C}$, feed water salinity of $35 \mathrm{ppt}$ and recovery ratio of $36 \%$, the MVCD system with six effects and energy recovery from the discharging fluids yielded a GOR of 5.0 and a second law efficiency of $3.8 \%$.
\end{abstract}

Keywords: Thermal desalination; Multiple-effect vapor chamber; Exergy analysis

\section{Introduction}

There is an increased demand for freshwater. It is projected that the global water demand will rise by $55 \%$ between 2000 and 2050 (from about 3,500 $\mathrm{km}^{3}$ in 2000 to about $5,500 \mathrm{~km}^{3}$ in 2050) [1]. On the other hand, wastewater management imposes a challenge in various municipal and industrial sectors. Recycling the wastewater for beneficial use can contribute to sustainable water management, considering the dramatic increase in freshwater demand in the years to come. Various technologies have been developed for water desalination over several decades. The commercially available desalination technologies can be grouped into two main categories: membrane desalination and thermal desalination. Reverse osmosis (RO) is currently the dominant membrane-based technology (and the dominant desalination technology overall). In RO systems the pressurized saline or wastewater is filtered by using a semi-permeable membrane that allows pure water to pass through [2]. However, due to the significant electricity demand of the RO systems, thermal desalination systems can be beneficial

* Corresponding author.

This is an Open Access article. Non-commercial re-use, distribution, and reproduction in any medium, provided the original work is properly attributed, cited, and is not altered, transformed, or built upon in any way, is permitted. The moral rights of the named author(s) have been asserted.

1944-3994/1944-3986 @ 2019 The Author(s). Published by Desalination Publications. 
whenever relatively cheap thermal energy is available, such as excess low-grade thermal energy from thermoelectric plants.

The present work is focused on thermal and exergetic evaluation of a novel compact and modular thermal desalination system. As such, a review of the most common thermal desalination technologies, as well as some modular and small-scale membrane-based technologies is presented in the following. The major thermal desalination technologies are the multi-stage flash (MSF) and multiple-effect distillation (MED). The MSF came into practice in the early 1960s and became popular due to its reliability and simplicity. The most important disadvantage of MSF is the relatively lower gained output ratio (GOR), defined as either a mass ratio (distillate mass to the mass of driving steam), or an energy ratio (total latent heat of evaporation of the distilled water to the input thermal energy) limited at about 11, resulting in relatively higher energy consumption. Compared to MSF, MED systems benefit from a significant increase in heat transfer area and the ability to operate at lower top brine temperatures, which helps to reduce corrosion and scaling [3]. The GOR ranges from 10 to 16 (mass ratio) in MED units, compared to 8-12 (mass ratio) for the MSF units. Unlike MSF, the MED process usually operates as a once-through system, and the absence of recirculation of large brine mass significantly reduces pumping requirements [4].

The thermal and economic performance of the MED processes has been studied extensively. Brogioli et al. [5] studied the principles governing energy efficiency and specific energy requirement intrinsic to thermal desalination processes from a thermodynamic point of view. They found that the energy efficiency of any thermal desalination process fulfills a limitation similar to the Carnot's law for heat engines. Al-Mutaz and Wazeer [6] developed mathematical models to analyze the performance of three configurations of the MED systems, namely parallel/cross, forward and backward feeds. Results showed that the parallel/ crossfeed scheme had the best performance characteristics with a higher GOR and lower specific heat consumption. El-Dessouky and Ettouney [7] presented a mathematical model for the forward feed multiple-effect evaporation desalination system and studied the effects of design and operating parameters on specific heat transfer area, GOR and specific flow rate of cooling water. They concluded that the GOR strongly depended on the number of effects. Druetta et al. [8] mathematically modeled and optimized the performance of a multiple-effect evaporation desalination system. They analyzed the flow patterns for the distillate and vapor. Results showed that the modification of the flow patterns could improve the process performance, reducing the process-specific total heat transfer area by $5 \%$ compared to conventional ones. They also observed that the novel flow patterns allowed for different ways of heat transfer area allocations. A non-uniform distribution of heat transfer area along the multiple effect evaporation desalination units led to increased system efficiency in comparison to a uniform distribution.

Fiorini and Sciubba [9] developed a model for thermodynamic and thermo-economic simulation of a MED plant. They considered a 14-effect configuration and a feed steam temperature of $75^{\circ} \mathrm{C}$. It was found that configurations characterized by high production and low efficiencies were preferable if feed steam was available at a relatively low cost. If steam was at a higher cost, configurations characterized by higher capital cost and higher efficiency were advantageous. Frantz and Seifert [4] also proposed a model for a parallel/cross-flow type MED plants. Their purpose was to optimize the efficiency of the desalination plant for a range of heating steam temperatures while considering a maximum tolerable increase in heat transfer surface area and a maximum cooling water mass flow rate. Results showed that the annual water production could be more than doubled if a heating steam temperature of $90^{\circ} \mathrm{C}$ was used instead of $65^{\circ} \mathrm{C}$.

Previous studies have also successfully found ways to enhance the efficiency of MED systems. A mathematical model of a MED-TVC (thermal vapor compression) system, which consisted of a set of forwarding feed vertical tube evaporators with TVC and a condenser was developed by Sagharichiha et al. [10]. They investigated the effect of the number of effects on GOR. Results showed that increasing the number of effects from 3 to 8 would increase the GOR value from 3.8 to 7.5. Gabriel et al. [11] developed a novel mathematical formulation for the modeling-based optimization of the MED water desalination process using TVC. Results indicated that salinity constraints on the effects could be overcome by novel flow distributions of the evaporator condensate. They also found that the optimal number of effects consistently changed with operating and economic conditions. Ophir and Lokiec [12] concluded that the low-temperature horizontal tube MED process was thermodynamically the most efficient of all thermal distillation processes. Wang and Lior [13] studied a low-temperature multi-effect evaporation system coupled with a lithium bromide-water $\left(\mathrm{LiBr}-\mathrm{H}_{2} \mathrm{O}\right)$ adsorption heat pump. They found that water production increase of $60 \%-78 \%$ could be achieved at the same heat source conditions due to the coupling. Saha et al. [14] conducted experiments on a hybridized adsorption cycle with MED. Results demonstrated that the water production improved by 2-3-folds in a system consisting of a three-effect MED and adsorption plant with the top brine temperature at $50^{\circ} \mathrm{C}$.

Recently, renewable sources such as solar thermal energy and photovoltaic, wind and geothermal energy have attracted significant attention as alternative heat sources for MED systems. Chorak et al. [15] experimentally studied a flat plate solar collector coupled with a MED unit. They investigated the influence of parameters such as the inlet hot water temperature and flow rate, feed water flow rate, and condenser vapor temperature on freshwater production and GOR. Results showed that the condenser vapor temperature had the greatest impact on the thermal efficiency of the MED unit, and increasing the feed water flow rate had the greatest influence on distillation production. Morad et al. [16] also developed a solar-powered desalination system using a flat plate collector and vacuum pump. Experimental results showed an increase in water production compared with conventional systems due to the coupling of the vacuum pump. Maximum freshwater production of $10.94 \mathrm{~L} / \mathrm{d}$ at a cost of 0.031 US $\$ / \mathrm{L}$ was achieved. Bataineh [17] studied the performance of a MED desalination plant combined with a thermal compressor driven by solar-generated 
steam. He found that solar energy was able to cover $68 \%$ of the thermal energy required by the desalination plant. The MED-TVC plant was capable of producing $35-45 \mathrm{~L} / \mathrm{m}^{2} / \mathrm{d}$ of freshwater when solar radiation was above $4.8 \mathrm{kWh} / \mathrm{m}^{2} / \mathrm{d}$.

Several membrane-based desalination technologies, including RO and membrane distillation systems, have also been investigated for modular and small scale applications. However, the majority of these systems are suited for brackish water treatment with relatively small salinities [18] that fall out of the application domain of the present work. A few studies have investigated membrane-based technologies for high salinity water treatment. Chiavazzo et al. [19] developed a solar-driven membrane-based system for passive and modular desalination. They used two hydrophilic layers separated by a hydrophobic microporous membrane. The evaporation and condensation occurred at the hydrophilic layers and the hydrophobic layer prevented the mixing between the pure permeate and the saline water. With 3 stages and an input salinity of $35 \mathrm{~g} / \mathrm{L}$ (seawater), water with negligible salt content was obtained at the rate of $1 \mathrm{l} / \mathrm{kWh}$ with a $10^{\circ} \mathrm{C}$ difference between the evaporator and condenser, corresponding to a GOR of 0.68. Elewa et al. [20] conducted an experimental study on a pervaporation system using a deacetylated cellulose acetate membrane. In the pervaporation system, the pure water from a heated saline feed water solution diffuses through a selective membrane that only allows the water molecules to cross. On the other side of the membrane, the relatively warmer permeated water evaporates due to partial pressure difference with the neighboring vapor. A maximum water flux of $5 \mathrm{~L} /\left(\mathrm{m}^{2} \mathrm{~h}\right)$ was obtained with an initial salt concentration of $120.8 \mathrm{~g} / \mathrm{L}$; the input energy for the system was not disclosed.

Traditionally, the MED systems are designed as stationary plants with no modularity, rendering them immobile. However, many applications of desalination require a portable and modular system to respond to the inherently transient quantity of saline or wastewater generation. On the other hand, RO systems are generally suitable for lower salinity feed water and thermally-driven membrane systems suffer from low permeation rates through the membrane [21]. The present study aims to address the above-mentioned issues by presenting a novel compact, portable, and modular thermal desalination system, which can be employed for onsite treatment of transient wastewater resources such as produced water in the oil and gas industry. The performance of the system is analyzed from the viewpoints of the first and second laws of thermodynamics by developing a detailed heat transfer model and an exergy analysis. The developed model yields the heat transfer rate, distilled water production rate, and temperature and pressure distribution across the system for the specified operating conditions. Appropriate forms of energy and exergy performance metrics are determined, which can be used to compare the system performance with alternative desalination solutions. In the following, the physical system and the modeling approach are described, followed by modeling results and related discussions.

\section{Description of the physical system}

The proposed design utilizes consecutive evaporation and condensation processes of saline water to produce distilled water. The system is comprised of a series of cascaded vapor chambers in which the condenser section of the upstream vapor chamber serves as the heat source for the evaporator section of the downstream "effect" (Fig. 1). The vapor chambers are vertically-positioned shallow metal boxes, where the two large vertical faces serve as the evaporator and condenser sections, and other faces are adiabatic. In this work, all effects have a similar configuration with a height of $H=0.5 \mathrm{~m}$, width of $W=1 \mathrm{~m}$ (Fig. 1), and depth of $L=0.02 \mathrm{~m}$ (spacing between the large faces), and are assumed to be made of $1 \mathrm{~mm}$ thick stainless steel 316 sheets for corrosion resistance. Each vapor chamber has one inlet for the feed water located on the top of the chamber and two bottom outlets; one for the brine and one for the distillate. The saline water enters the vapor chambers in a parallel feed arrangement, that is, each chamber is directly connected to the saline water supply line. The feed water first goes through a heat exchanger (the down-condenser), in which the heat rejected from the last effect of the multipleeffect vapor chamber distillation (MVCD) system preheats the input water. The preheated feed water then goes through a partial degassing process described below.

The feed water contains dissolved non-condensable gasses. The build-up of non-condensable gasses inside the vapor chambers must be mitigated for the stable operation of the evaporative desalination systems. In conventional systems, removal of non-condensable gasses is accomplished either by using a steam jet ejector or mechanical vacuum pumps. The former requires high steam pressure which might not be available for a small-scale system like the one presented in this work. A vacuum pump will significantly add to the capital cost of the system, especially considering that the proposed MVCD system is geared toward smallscale applications with a low capital cost. As such, to mitigate the build-up of non-condensable gasses in the present design, two simple complementary approaches are devised; (i) adding a simple deaerator unit after the down-condenser to lower the air content of the inlet water and (ii) an ad-hoc degassing procedure described later in this section. The deaerator unit works by increasing the feed water temperature and thereby decreasing the air solubility in water. The removed air from the heated water is then vented and the partially degassed water goes through a heat exchanger where it transfers heat to the feed water entering the deaerator unit. The deaerator unit and flow arrangement in and out of it are shown in Fig. 1.

The partially degassed feed water passes through the pressure reducing valves before entering the effects for pressure equilibrium with the vapor inside. Depending on whether heat recovery from the discharging fluids is enabled or not, the feed water may go through another heat exchanger before passing through the pressure reducing valve.

Inside the chambers, the preheated feed water flows down the heated wall. At the upper section of the wall, the water temperature increases to the saturation value by heat transfer from the wall. In the remaining portion of the wall, the saturated water is evaporated by absorbing heat from the wall. The saturated vapor fills the interior space and comes in contact with the relatively colder side of the chamber, where condensation occurs. The condensed water is collected at the bottom of the chamber and is discharged after 


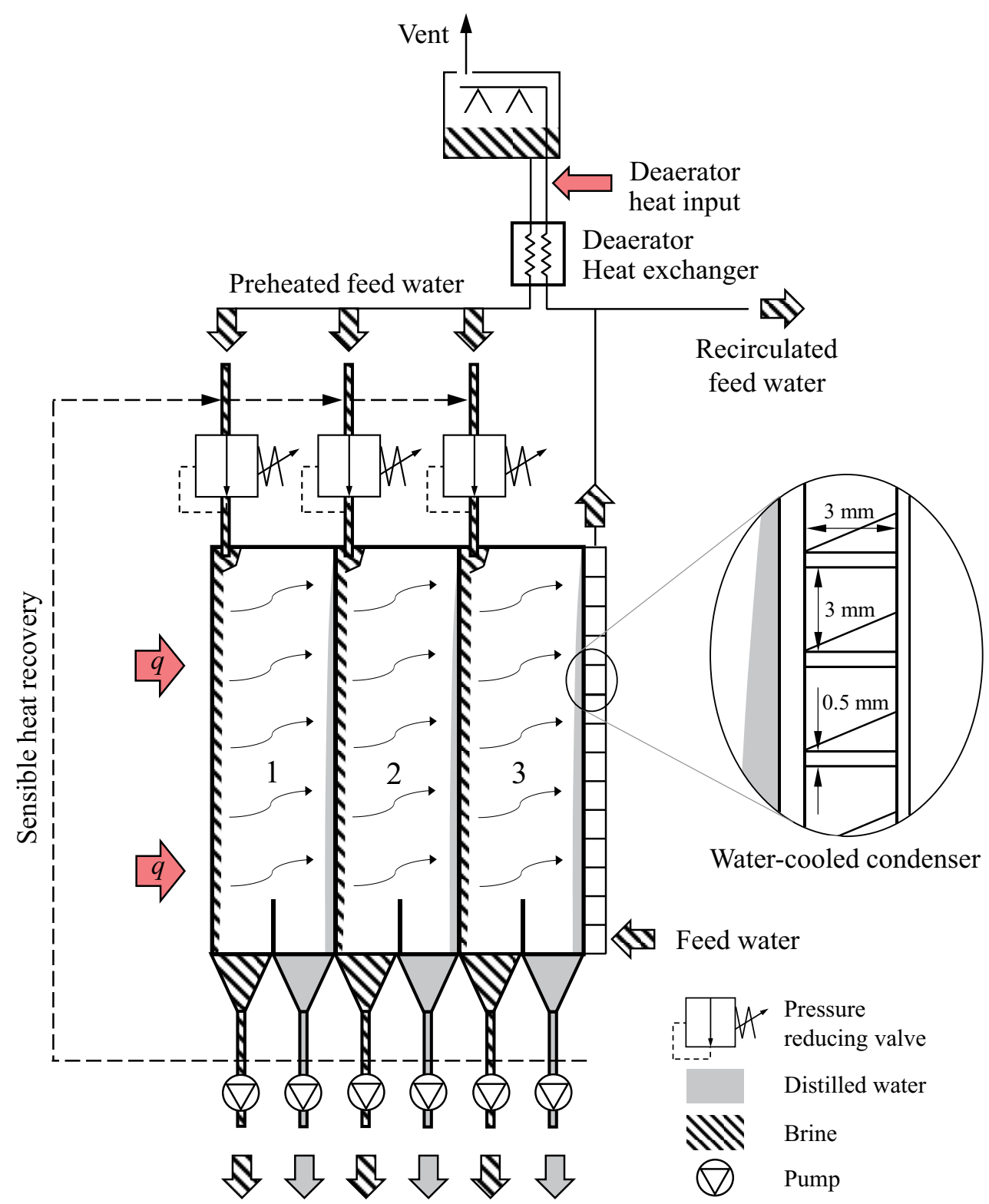

Fig. 1. Schematic design of a multiple-effect vapor chamber distillation system with three effects.

its pressure is brought to equilibrium with the ambient via a pump. Simultaneously, the non-evaporated portion of the feed water is discharged after its pressure is increased to the atmospheric value. As schematically shown by the dashed line in Fig. 1, the thermal energy content of the discharging brine and distilled water can be recovered to further preheat the feed water before entering the chamber. In this work, the system performance with and without the sensible heat recovery from the discharging brine and distillate is analyzed. When enabled, the sensible heat recovery is assumed to be realized using heat exchangers with the effectiveness of $\varepsilon=0.5$.

Inside chamber 2, the falling liquid film on the evaporator wall (separating chambers 1 and 2) absorbs the heat of condensation of the distilled water in chamber 1. The absorbed heat is used to first increase the feed water temperature to the saturation temperature, and then to evaporate it. As such, condensation and evaporation occur simultaneously on opposite sides of the separating wall between chambers 1 and 2 at slightly different temperatures and pressures. The saturated vapor created in chamber 2 moves to the condenser side (right-hand side wall of chamber 2 in Fig. 1), where it condenses due to the relatively lower temperature of the condenser wall. The same configuration is repeated until the temperature of the saturated vapor in the last chamber approaches that of the cooling medium, that is, the feed water.

The external side of the cold wall in the last effect of the MVCD system is designed as a condenser unit in which the heat of condensation of the vapor in the last effect preheats the feed water. The condenser is comprised of stainless steel 316 fins extending along the width of the wall. The fins are 
assumed to have a thickness of $0.5 \mathrm{~mm}$, a height of $3 \mathrm{~mm}$, and center-to-center spacing of $3.5 \mathrm{~mm}$ (see the inset in Fig. 1). A flat plate is assumed to be placed on top of the fin array to enclose the finned space and to create flow passage for the feed water.

It is noted that the vapor temperature within each chamber is smaller than the evaporator wall temperature and greater than the condenser wall temperature of that chamber [22]. The pressure inside the chamber is equal to the saturation pressure of the water vapor at the corresponding vapor temperature. Thus, as long as no non-condensable gases are present within a chamber, the pressure (and temperature) of the vapor in the chamber is controlled by the wall temperatures of the chamber.

The partial degassing process described earlier does not remove all the non-condensable gasses. The non-condensable gasses entering the effects are released into the internal space due to lower pressure inside the effects. For ondemand venting of the non-condensable gasses, relief valves are embedded on the walls separating neighboring effects. These one-way valves allow flow from the high-pressure side to the low-pressure side when the high pressure increases beyond a certain value (referred to as cracking pressure). During the venting process, all the input and output valves are closed except the feed water inlet and brine outlet valves in the first effect. The falling film is established on the heated wall in the first effect and the wall temperature is increased to a value greater than $100^{\circ} \mathrm{C}$. The pressure inside chamber 1 increases due to evaporation and eventually exceeds the atmospheric pressure (due to evaporation at a temperature greater than $100^{\circ} \mathrm{C}$ ). During this time, the feed water flows into the first effect is maintained via a pump. The relief valve between the first and second chambers opens and vapor and non-condensable gasses fill chamber 2 . Continuing evaporation from the heated wall of chamber 1 increases the pressure in chambers 1 and 2 . When the pressure inside chamber 2 exceeds the cracking pressure of the relief valve between chambers 2 and 3, vapor and non-condensable gasses flow into the 3rd chamber. Similarly, other downstream chambers are filled with a mixture of vapor and non-condensable gasses one after the other. The upper wall of the last effect is embedded with a relief valve that opens to the ambient. When the pressure in the last effect exceeds the atmospheric pressure, the relief value opens and the non-condensable gasses and vapor are released to the ambient. The venting continues for a short period to ensure that all the noncondensable gasses are vented and the internal space of all the effects is filled with pure vapor. The described method is simple and does not add to the capital cost significantly. The drawback is the non-continuous operation which requires disruption of normal operation. However, considering the small-scale scope of the present design, the method is deemed viable.

The system can work with a variety of heat sources, including natural gas, low-pressure steam from a cogeneration power plant or solar energy. The salt deposition problems on the evaporator walls and related maintenance needs are minimized since the majority of vaporization occurs at the interface of the liquid film and saturated vapor. It is noted that despite the fundamental similarity of the present system and conventional MED systems, several differences exist between the two. Most importantly, in the present design, the evaporation and condensation of the feed water entering an effect occur within the same effect, as opposed to MED systems in which the feed water evaporated in effect $n$ condenses in effect $n+1$. As such, in the present design, neighboring effects are coupled only through the heat transfer. This leads to a significantly shorter path for vapor transport and a more compact design compared to conventional MED systems. Also, unlike the MED systems, there is no counter-flowing feed water and vapor flow, which leads to further simplified design.

\section{Model development}

This section describes the thermal, mass transfer, and exergy models developed for the analysis of the MVCD system. The model accounts for the various physical phenomena occurring in the system including sensible heat addition to the feed water, filmwise evaporation, and condensation, heat conduction across the heat transfer surfaces, saturation temperature change with salinity, thermal analysis of the condenser, and accumulation of the non-condensable gasses. The thermophysical properties of pure and saline water as a function of temperature, pressure, and salinity are obtained from Nayar et al. [23] and are used in the modeling. The following assumptions are adopted in the development of the heat transfer model: steady-state, negligible heat loss during the degassing process or from the walls, negligible interfacial thermal resistances due to evaporation and condensation, negligible contact thermal resistances, zero solutes in the purified water, and negligible fouling effects.

The conservation of mass for the $n$th effect can be written as:

$\dot{m}_{f, n}=\dot{m}_{b, n}+\dot{m}_{d, n}$

where $m$ is the mass flow rate and subscripts $f, b$, and $d$ denote the feed water, discharged brine and distillate, respectively. The conservation of mass for the dissolved salts in the $n$th effect is:

$\dot{m}_{f, n} S_{f, n}=\dot{m}_{b, n} S_{b, n}$

where $S_{f}$ and $S_{b}$ are the salinity of the feed water and brine, respectively. Salinity is defined as the mass of salts dissolved in the unit mass of the solution and is usually measured in ppt (grams of salt per kilogram of solution) or ppm (milligrams of salt per kilogram of solution). It is noted that Eq. (2) is written based on the assumption of salt-free distilled water.

The energy balance for effect $n$ can be written as:

$q_{\text {in }, n}+\dot{m}_{f, n} h_{f, n}=\dot{m}_{b, n} h_{b, n}+\dot{m}_{d, n} h_{d, n}+q_{\text {out }, n}$

where $q_{\text {in }}$ and $q_{\text {out }}$ are the heat input to- and output from the $n$th effect and $h$ denotes the specific enthalpy of the fluid streams. The heat output from the effect $n$ is related to the condensation mass flow rate in the effect and is equal to the heat input to the downstream effect:

$q_{\text {out }, n}=q_{\text {in }, n+1}=\dot{m}_{d, n} h_{\mathrm{fg}, \text { cond }, n}$ 
where $h_{\mathrm{fg}, \mathrm{cond}}$ denotes the latent heat of condensation of distilled water. The energy balance of Eq. (4) is written using the assumption that the distilled water exits the effect at saturation temperature. By using Eqs. (4) and (1), Eq. (3) can be rearranged to obtain the distillation rate in effect $n$ :

$\dot{m}_{d, n}=\frac{q_{\mathrm{in}, n}+\dot{m}_{f, n}\left(h_{f, n}-h_{b, n}\right)}{h_{\mathrm{fg}, \text { cond }, n}+h_{d, n}-h_{b, n}}$

The enthalpy of each of the fluid streams depends on its temperature, salinity, and pressure. Except for the salinity of the feed water and the distilled water which are readily known, all other properties needed to determine the enthalpy of the water streams are unknown and must be obtained during the solution procedure. These include the temperature and pressure of the fluid streams in and out of chambers and salinity of the brine. It is noted that the discharging brine and distilled water are assumed to leave the chambers at their corresponding saturation temperatures. However, the saturation conditions are not known a priori and are calculated using the thermal network explained in the following.

Fig. 2 shows the representative thermal network of the $n$th effect of a MVCD system. The input heat to each effect is divided into two parts; a sensible heat portion that increases the temperature of the feed water to the saturation temperature, and a latent heat portion that is transferred to the next effect through evaporation and condensation of the water. The major temperature drops in the latent heat transfer path are related to the following: (i) conduction across the solid surfaces, (ii) heat transfer through the evaporating and condensing liquid films, and (iii) saturation temperature drop due to salinity change.

Considering Fig. 2, the wall temperature at the interface with the evaporating liquid film can be written as:

$T_{w, \text { evap }, n}=T_{w, \text { cond }, n-1}-q_{\text {in }, n} R_{w, n}$

where $T_{w, \text { evap } n}$ and $T_{w, \text { cond, } n-1}$ are the wall temperatures at the interface with the evaporating liquid film in the $n$th effect and condensing liquid film in effect $n-1$, respectively, and $R_{w}$ is the wall thermal resistance. Similarly, the saturation temperature at the interface of the evaporating liquid film and the vapor, $T_{s, \text { evap }}$ can be related to the wall temperature at the interface with the evaporating liquid film:
$T_{s, \text { evap }, n}=T_{w, \text { evap }, n}-q_{\mathrm{in}, n+1} R_{\mathrm{fe}, n}$

where $R_{\mathrm{fe}}$ is the thermal resistance associated with heat transfer across the evaporating liquid film. A similar expression can be written for the temperature at the interface of the cold wall and the condensing liquid film (see Fig. 2):

$T_{w, \text { cond }, n}=T_{s, \text { cond }, n}-q_{\mathrm{in}, n+1} R_{\mathrm{fc}, n}$

The saturation temperature drop from the surface of the evaporating liquid film to the surface of the condensing liquid film is equal to the boiling point elevation, $\Delta T_{\text {bpe }}=T_{s, \text { evap }, n}-T_{s, \text { cond }, n}$. The boiling point elevation is obtained by calculating the difference between the saturation temperature of distilled water and brine at the vapor pressure inside the chamber.

To use Eqs. (7) and (8), thermal resistances associated with the evaporating and condensing liquid films, $R_{\mathrm{fe}}$ and $R_{\mathrm{fc}}$ are to be determined. These resistances depend on the flow regime of the liquid film, which is a function of the film Reynolds number. The film Reynold number is usually expressed as $\operatorname{Re}=4 \Gamma / \mu_{\nu}$, where $\Gamma$ denotes the liquid mass flow rate per unit width of the wall [24]. Three flow regimes of wave-free laminar, wavy laminar, and turbulent can be identified for the liquid films, associated with relatively small, transitional, and large film Reynolds numbers [24,25]. Chun and Seban [26] suggested the following empirical correlation to determine the transitional Reynolds number from the wave-free laminar to wavy laminar regimes as a function of Kapitza number:

$$
\operatorname{Re}_{\text {wavy }}=2.43 \mathrm{Ka}^{-1 / 11}, \quad \mathrm{Ka}=\frac{\mu_{l}^{4} g}{\left(\rho_{l}-\rho_{v}\right) \sigma^{3}}
$$

Transition to fully turbulent film can be predicted using the following empirical correlation presented by Stephan [27]:

$\operatorname{Re}_{\text {turb }}=5840 \operatorname{Pr}^{-1.05}$

After the flow regime is determined, the liquid film heat transfer coefficient on the evaporator and condenser walls is calculated from the corresponding correlations. The evaporating liquid film heat transfer coefficient for the wave-free laminar regime is determined from [24]:

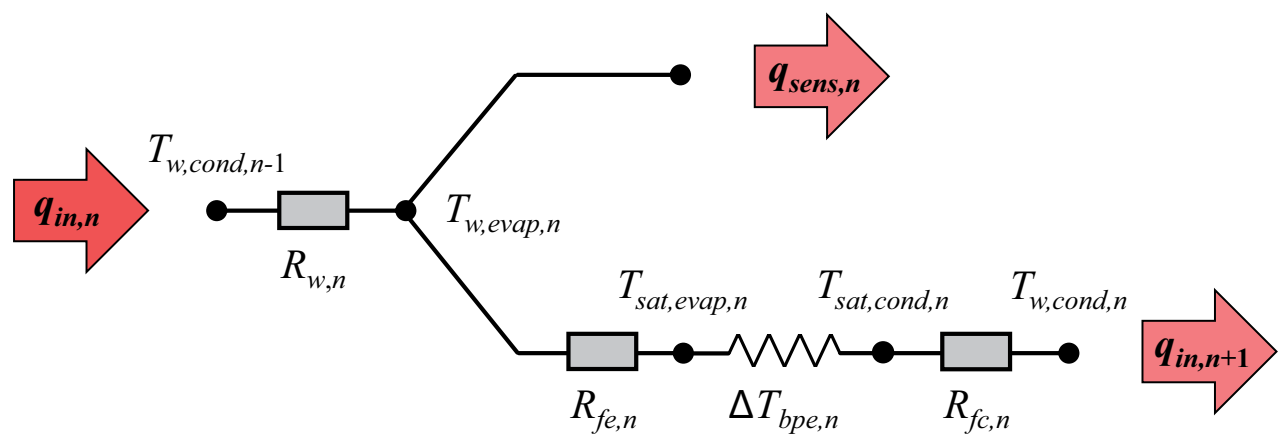

Fig. 2. Thermal network representation of the heat transfer through an effect in an MVCD system. 
$h_{\mathrm{fe}}=\left(\frac{4}{3}\right)^{4 / 3} k_{l}\left[\frac{\rho_{l}\left(\rho_{l}-\rho_{v}\right) g}{\mu_{l}^{2}}\right]^{1 / 3} \frac{\left(\operatorname{Re}_{0}-\operatorname{Re}_{y}\right)}{\left(\operatorname{Re}_{0}^{4 / 3}-\operatorname{Re}_{y}^{4 / 3}\right)} ; \operatorname{Re}_{0} \operatorname{Re}_{\text {wavy }}$

where $\operatorname{Re}_{0}$ is the film Reynolds number at the top of the wall and $\operatorname{Re}_{y}$ is the film Reynolds number at a location $y$ below the starting point of evaporation, determined from:

$\operatorname{Re}_{y}^{4 / 3}=\operatorname{Re}_{0}^{4 / 3}-4\left(\frac{4}{3}\right)^{4 / 3} \frac{k_{l} y\left(T_{w, \text { evap }}-T_{\text {sat }}\right)}{\mu_{l}^{4 / 3} h_{\mathrm{fg}}}\left[\frac{\rho_{l}\left(\rho_{l}-\rho_{v}\right) g}{3 \mu_{l}}\right]^{1 / 3}$

The film heat transfer coefficient in the wavy laminar regime can be calculated from [24]:

$h_{\mathrm{fe}}=k_{l}\left[\frac{\rho_{l}\left(\rho_{l}-\rho_{v}\right) g}{\mu_{l}^{2}}\right]^{1 / 3} \frac{\left(\operatorname{Re}_{0}-\operatorname{Re}_{y}\right)}{\left(\operatorname{Re}_{0}^{1.22}-\operatorname{Re}_{y}^{1.22}\right)} ; \operatorname{Re}_{\text {wavy }}<\operatorname{Re}_{0}<\operatorname{Re}_{\text {turb }}$

where $\operatorname{Re}_{y}$ is:

$\operatorname{Re}_{y}^{1.22}=\operatorname{Re}_{0}^{1.22}-4 \frac{k_{l} y\left(T_{w, \text { evap }}-T_{\text {sat }}\right)}{\mu_{l} h_{f g}}\left[\frac{\rho_{l}\left(\rho_{l}-\rho_{v}\right) g}{\mu_{l}^{2}}\right]^{1 / 3}$

The turbulent film heat transfer coefficient is predicted from [24]:

$h_{\mathrm{fe}}=0.00228 k_{l}\left[\frac{\rho_{l}\left(\rho_{l}-\rho_{v}\right) g}{\mu_{l}^{2}}\right]^{1 / 3} \frac{\left(\operatorname{Re}_{0}-\operatorname{Re}_{y}\right)}{\left(\operatorname{Re}_{0}^{0.6}-\operatorname{Re}_{y}^{0.6}\right)} \operatorname{Pr}^{0.65} ; \operatorname{Re}_{0}>\operatorname{Re}_{\text {turb }}$

where $\operatorname{Re}_{y}$ for the turbulent film is:

$\operatorname{Re}_{y}^{0.6}=\operatorname{Re}_{0}^{0.6}-0.00912 \frac{k_{l} y\left(T_{w, \text { evap }}-T_{\text {sat }}\right)}{\mu_{l} h_{\mathrm{fg}}}\left[\frac{\rho_{l}\left(\rho_{l}-\rho_{v}\right) g}{\mu_{l}^{2}}\right]^{1 / 3}$

Similarly, the heat transfer coefficient of the condenser section for the wave-free laminar, wavy laminar, and turbulent film regimes is determined from the following equations, respectively [25]:

$h_{\mathrm{fc}}=0.943 \frac{k_{l}}{\left(\frac{\mathrm{v}_{l}^{2}}{g}\right)^{1 / 3}} P^{-0.25} ; \quad P \lesssim 15.8$

$h_{\mathrm{fc}}=\frac{k_{l}}{\left(\frac{v_{l}^{2}}{g}\right)^{1 / 3}}\left(\frac{1}{P}\right)(0.68 P+0.89)^{0.82} ; 15.8 \lesssim P \lesssim 2530$

$h_{\mathrm{fc}}=\frac{k_{l}}{\left(\frac{v_{l}^{2}}{g}\right)^{1 / 3}}\left(\frac{1}{P}\right)\left[(0.68 P+0.89) \operatorname{Pr}_{l}^{0.5}+89\right]^{4 / 3} ; \quad \mathrm{P} \gtrsim 2530, \operatorname{Pr} \gtrsim 1$ where $P$ is defined as:

$$
P=\frac{k_{l} H\left(T_{\mathrm{sat}}-T_{w, \text { cond }}\right)}{\mu_{l} h_{\mathrm{fg}}^{\prime}\left(\frac{\mathrm{v}_{l}^{2}}{g}\right)^{1 / 3}}
$$

In the above equations $\mathrm{Q}, k, v, \mu, \mathrm{Pr}$, and $h_{\mathrm{fg}}$ denote the density, thermal conductivity, kinematic viscosity, dynamic viscosity, Prandtl number and heat of vaporization, respectively, and subscripts $l$ and $v$ are related to the liquid and vapor phases. Also, $g$ denotes the gravitational acceleration, $H$ is the height of the wall, $T_{w, \text { evap }}\left(T_{w, \text { cond }}\right)$ represents the evaporator (condenser) wall temperature, and $T_{\text {sat }}$ is the saturation vapor temperature. In Eq. (20), $h_{\mathrm{fg}}{ }^{\prime}$ is a modified latent heat of vaporization introduced instead of $h_{\mathrm{fg}}$ to account for the effect of liquid subcooling and thermal advection. Rohsenow [28] recommended $h_{\mathrm{fg}}{ }^{\prime}=h_{\mathrm{fg}}+0.68 c_{l}\left(T_{\mathrm{sat}}-T_{w}\right)$.

\subsection{Sensible heat transfer to the feed water}

In each effect, the temperature of the input feed water is increased from the inlet valve to the saturation temperature. The sensible heating occurs on the top section of the wall, where the feed water enters the effect as liquid film falling down the heated wall. As such, a portion of the upper section of the wall does not participate in evaporation. Calculation of the length required for sensible heating is important because it directly affects the thermal resistance of the evaporating liquid film by decreasing the evaporation surface area. The required sensible heating length, $H_{\text {sh }^{\prime}}$ in the $n$th effect can be determined from: $H_{\mathrm{sh}}, n=\dot{m}_{f, n} c_{f, n}\left(T_{s, \mathrm{evap}, n}-T_{f, \mathrm{in}, n}\right) H / q_{\mathrm{in}, n^{\prime}}$ where $H$ is the total height of the heated wall. After $H_{\mathrm{sh}}$ is calculated for an effect, the height of the evaporating liquid film is determined as $y=H-H_{\text {sh' }^{\prime}}$ and is used in Eqs. (12), (14) and (16). It is noted that for all the cases studied in this work, the modeling results showed that the sensible heating height varied from 30 to $50 \mathrm{~mm}$ in the first effect to 10 to $20 \mathrm{~mm}$ in the last effect with an average height of about $20 \mathrm{~mm}$. Due to sub-saturated temperature in this section, condensation may occur. However, this effect is deemed negligible due to the relatively short height of the sub-statured section (about $5 \%$ of the wall height), which will be even shorter if the heat released due to condensation was accounted for.

\subsection{Condenser modeling}

The heat transfer between the down-condenser unit and the cooling water is analyzed using the effectiveness-number of transfer units (NTU) method, along with the overall fin efficiency concept. The overall thermal resistance of the condenser is the sum of the base plate resistance and the parallel combination of resistances of the fins and the un-finned portion of the base plate exposed to the cooling water; $R_{\text {cond }}=R_{w \text {,base }}+R_{\text {fin-array }}$. The overall thermal resistance of the fin array (fins + unfinned portion of the base) is $R_{\text {fin-array }}=$ $1 /\left(h_{0} h A_{0}\right)$, where $h$ is the convective heat transfer coefficient between the cooling water and the fin array, and $A_{0}$ and $h_{0}$ are the total heat transfer surface area and the overall efficiency of the fin array, respectively. The overall fin efficiency can be written as $h_{0}=1-\left(1-h_{f}\right) A_{f} / A_{0^{\prime}}$ where $h_{f}$ and $A_{f}$ are 
the efficiency and surface area of a single fin. The single fin efficiency is calculated from the appropriate equation for a fin with adiabatic tip [25].

If $R_{\text {cond }}$ is to be used, the log-mean temperature of the cooling water must be applied as the heat sink temperature. However, the log-mean temperature is a function of the heat rejection rate, which is not known a priori. Alternatively, the effectiveness-NTU method allows for using the inlet temperature of the cooling water instead of the log-mean temperature. In the effectiveness-NTU method, the heat transfer rate is calculated as $q=\varepsilon C_{\min }\left(T_{w, \text { cond }, N}-T_{c w, i n}\right)$, where $\mathrm{e}$ is the heat exchanger effectiveness, $C_{\min }$ is the minimum heat capacity rate equal to the product of the cooling water mass flow rate and its specific heat, and $T_{\mathrm{cw}, \text { in }}$ is the inlet temperature of the cooling water. Accordingly, a condenser thermal resistance can be defined as $R_{\mathrm{cond}, \varepsilon-\mathrm{NTU}}=1 /\left(\varepsilon C_{\min }\right)$. The driving temperature difference associated with $R_{\text {cond }, \varepsilon-\mathrm{NTU}}$ uses the inlet temperature of the cooling water instead of the log-mean temperature and hence is independent of the heat rejection rate. The effectiveness, $\mathrm{e}$, is a function of the number of transfer units, defined as NTU $=1 /\left(R_{\text {cond }} C_{\min }\right)$. Considering a constant baseplate temperature, the effectiveness can be calculated as e $=1-\exp (-\mathrm{NTU})$.

\subsection{Effect of non-condensable gasses}

As noted in Section 2, a deaerator unit and an on-demand degassing procedure are devised to mitigate the effect of non-condensable gasses. The heat requirement of the deaerator depends on the temperature rise of the feed water through the deaerator, as well as the effectiveness of the deaerator heat exchanger:

$q_{\text {deaerator }}=\left(1-\varepsilon_{\mathrm{HX}, \text { deaerator }}\right) \dot{m}_{f} \mathcal{c}_{f}\left(T_{\text {out, deaerator }}-T_{\mathrm{cw}, \text { out }}\right)$

where $\varepsilon_{\mathrm{HX} \text {,deaerator }}$ shows the effectiveness of the deaerator heat exchanger. For a specified deaerator outlet temperature, the temperature of the partially degassed feed water entering the effects, $T_{f, \text { in' }}$ can be found from:

$T_{f, \text { in }}=T_{\text {out }, \text { deaerator }}-\varepsilon_{\mathrm{HX}, \text { deaerator }}\left(T_{\text {out, deaerator }}-T_{\mathrm{cw}, \text { out }}\right)$

The amount of the air dissolved in the water is a function of its temperature and pressure. Considering atmospheric pressure in the deaerator and assuming that the input feed water is fully saturated with air, the volume ratio of air to liquid water, $V_{r}$, at various temperatures can be found from the following equation obtained from curve fitting to the data in [29].

$V_{r}=-5.0696 \times 10^{-8} \mathrm{~T}^{3}+8.6594 \times 10^{-6} \mathrm{~T}^{2}-6.4212 \times 10^{-4} \mathrm{~T}+2.8093$

where $T$ is in $\left({ }^{\circ} \mathrm{C}\right)$. Substituting the outlet temperature of the deaerator, $T_{\text {out,deaerator }}$ in Eq. (23), the air content of the feed water entering the effects can be determined. The major portion of the input air will be released inside the effects due to the temperature increase and pressure reduction. Here, the worst-case scenario is considered where the entire air content of the inlet water is assumed to be released into the chambers.
Knowing $V_{r}$ and the mass flow rate of the feed water into the MVCD, the accumulation rate of air and the total air volume in each effect at a specific time during the operation can be determined. At a time $t$, the average mole fraction of air, $\bar{x}_{\text {air }}(t)$, in each effect can be obtained by dividing the total air volume in that effect by the internal volume of the effect.

$\bar{x}_{\text {air }}(t)=\frac{\dot{m}_{f} V_{r} t}{\rho_{f} L H W}$

The average vapor mole fraction can then be calculated as $\bar{x}_{v}(t)=1-\bar{x}_{\text {air }}(t)$.

The evaporated water from the heated wall must diffuse through the air to reach the cold wall. The mass transfer resistance induced by the air leads to a negative mole fraction gradient for vapor from the heated wall to the cooled wall. The reduced vapor mole fraction at the condensation site decreases the saturation pressure for the condensing vapor compared to the evaporating vapor. The reduction of saturation pressure creates an additional temperature drop due to the coupling between the saturation pressure and temperature. The vapor mass flux from the heated wall to the cooled wall, $m_{v}^{\prime \prime}$, can be determined from [25]:

$m_{v}^{\prime \prime}=\frac{M_{w} C D_{\mathrm{av}}}{L} \ln \left(\frac{1-x_{v, L}}{1-x_{v, 0}}\right)$

where $M_{w^{\prime}} C, D_{\mathrm{av}} x_{v, L}$ and $x_{v, 0}$ are the molecular mass of water, concentration of the air-water mixture in the effect, binary mass diffusion coefficient of air and water vapor, and the mole fractions of water vapor at the heated and cooled walls, respectively, and $L$ is the spacing between the heated and cooled walls (as noted in Sec. 2, for the present design $L=0.02 \mathrm{~m}$ ). Considering the water vapor and air mixture as an ideal gas, the mixture concentration in each effect, $C$, can be found from the equation of state of ideal gasses using the effect's temperature and pressure. It is noted that for the temperatures and pressures present in this work, the deviation of the water vapor from the ideal gas behavior is less than $1.5 \%$. The diffusion coefficient, $D_{\mathrm{av}}$ can be found for standard conditions and modified for the specific temperature and pressure using appropriate equations (e.g. Eq. (14.14) in [25]).

To use Eq. (25), $x_{v, L}$ and $x_{v, 0}$ are needed. For a binary mixture with one non-condensable component, the mole fraction distribution of the condensable species can be obtained from:

$x_{v}=\left(1-x_{v, 0}\right)\left(\frac{1-x_{v, L}}{1-x_{v, 0}}\right)^{\frac{x}{L}}, \quad 0<x<L$

The average vapor mole fraction at time $t, \bar{x}_{v}(t)$, can be determined by integrating the above equation:

$\bar{x}_{v}(t)=\frac{1}{L} \int_{0}^{L}\left(1-x_{v, 0}\right)\left(\frac{1-x_{v, L}}{1-x_{v, 0}}\right)^{\frac{x}{L}} d x$

Since $\bar{x}_{v}(t)$ is readily known, Eqs. (25) and (27) could be solved numerically to obtain $x_{v, 0}$ and $x_{v, L}$ at time $t$, provided that the vapor mass flux was known. Determination of the 
vapor mass flow rate (that is equal to the distilled water production rate) requires an iterative procedure. As such, the determination of the effect of non-condensable gasses on the reduction of the distillation rate is integrated into the iterative solution procedure described in the following.

\subsection{Solution procedure}

The solution procedure started from the first effect, for which the hot-end temperature was specified. The operation duration and the temperature at the deaerator outlet were also specified. Using an initial guessed temperature distribution, the specific enthalpies of the brine and distilled water were determined from available thermodynamic libraries [23,30]. Also, an initial guessed value for the input heat to the first effect was employed to initiate the solution procedure. Using the initial values for the enthalpies and the input heat, the distilled water production in the first effect was determined from Eq. (5), and the input heat to the second chamber was calculated from Eq. (4). Next, the temperatures and pressures across the first effect were updated using Eqs. (6)-(8). The calculated vapor mass flow rate and temperatures and pressures inside the first effect, along with its average vapor mole fraction, were used to determine the mole fractions of water vapor at the heated and cooled walls using Eqs. (25) and (27). The vapor volume fractions at the heated and cooled walls were used to update the evaporation and condensation temperatures within the first effect. The initial guessed temperatures were replaced with new temperatures and the above procedure was repeated until the temperature distribution inside the effect converged.

A similar procedure was followed for the other effects to determine the temperature distribution, as well as the heat input to the corresponding downstream effects. Finally, the energy balance associated with heat rejection from the last effect to the cooling water, $q_{\text {out }, N}$, was applied:

$q_{\mathrm{out}, \mathrm{N}}=\dot{m}_{d, N} h_{\mathrm{fg}, \mathrm{cond}, N}=\frac{T_{w, \text { cond }, \mathrm{N}}-T_{\mathrm{cw}, \mathrm{in}}}{R_{\mathrm{cond}, \varepsilon-\mathrm{NTU}}}$

Using the latest calculated values of $q_{\text {out }, N}$ and $T_{w, \text { cond }, N}$ and the known thermal resistance of the condenser, Eq. (28) was used to predict a coolant inlet temperature, $T_{\mathrm{cw}, \mathrm{in}}$. The predicted coolant inlet temperature was then used to correct the initial guess for the input heat to the first effect; if the predicted coolant water inlet temperature was greater (smaller) than its actual value, and the difference was greater than the desired convergence threshold, the input heat transfer rate was increased (decreased) incrementally. The modified input heat and the temperature distributions from the last iteration were used to start a new iteration. This procedure was continued until the predicted coolant inlet temperature approached the actual value within the desired convergence accuracy. A temperature difference smaller than $10^{-3{ }^{\circ}} \mathrm{C}$ was considered sufficiently accurate. A MATLAB code was developed to execute the above iterative solution procedure.

\subsection{Performance metrics}

The performance of the desalination system is quantified from the viewpoints of the first and second laws of thermodynamics using two performance metrics, namely the GOR and the second law efficiency. The GOR is defined as [31]:

$$
\mathrm{GOR}=\frac{\dot{m}_{d} h_{\mathrm{fg}}}{q}
$$

where $q$ is the sum of the input heat to the first effect and the deaerator heat input, and $h_{\mathrm{fg}}$ is the latent heat of vaporization of pure water at the standard pressure and temperature. The general exergy balance equation for a system operating under steady-state flow conditions is:

$\dot{\mathrm{E}} \mathrm{x}_{\mathrm{in}}=\dot{\mathrm{E}} \mathrm{x}_{\text {out }}+\dot{\mathrm{E}} \mathrm{x}_{\mathrm{des}}$

For a thermal desalination system with negligible work interactions, the above exergy balance is expanded as:

$\dot{\mathrm{E}} \mathrm{x}_{\mathrm{th}, \text { in }}+\dot{\mathrm{E}} \mathrm{x}_{f}=\dot{\mathrm{E}} \mathrm{x}_{\mathrm{th}, \text { out }}+\dot{\mathrm{E}} \mathrm{x}_{d}+\dot{\mathrm{E}} \mathrm{x}_{b}+\dot{\mathrm{E}} \mathrm{x}_{\mathrm{des}}$

where $\dot{\mathrm{E}} \mathrm{x}_{\text {th }}$ denotes the thermal exergy, $\dot{\mathrm{Ex}} \mathrm{f}_{f^{\prime}} \dot{\mathrm{E}} \mathrm{x}_{d^{\prime}}$ and $\dot{\mathrm{Ex}} \mathrm{x}_{b}$ denote the exergy flows associated with the feed, distillate and brine streams, respectively, and $\dot{E} x_{\text {des }}$ is the rate of exergy destruction. Several definitions of second law efficiencies have been reported in the literature [32]. One type of second law efficiency is defined as the ratio of the output exergy to the input exergy:

$\eta_{I I, 1}=\frac{\dot{\mathrm{E}} \mathrm{x}_{\text {out }}}{\dot{\mathrm{E}} \mathrm{x}_{\text {in }}}=1-\frac{\dot{\mathrm{E}} \mathrm{x}_{\mathrm{des}}}{\dot{\mathrm{E}} \mathrm{x}_{\text {in }}}$

This definition is more relevant when the identification of the exergy destruction sources within the system are of primary interest. In another definition, the second law efficiency is determined as the ratio of the exergy of the useful product of the desalination system (i.e. the purified water) to the required exergy input. In a thermal desalination system, thermal energy supplies the required exergy input; thus, the exergy efficiency can be written as [33]:

$\eta_{I I, 2}=\frac{\dot{\mathrm{Ex}} \mathrm{E}_{d}}{\dot{\mathrm{E} x_{\text {th }, \text { in }}}}=\frac{\dot{m}_{d}\left(e x_{d}\right)}{q\left(1-\frac{T_{0}}{T_{h}}\right)}$

where $\mathrm{ex}_{d}$ is the exergy of the distilled water per unit mass, and $T_{0}$ and $T_{h}$ are the dead state temperature and the temperature at which thermal energy is supplied to the system, respectively. It is noted that the efficiencies obtained from Eqs. (32) and (33) are identical if the exergy content of all the heat and flow streams leaving the desalination system, except the distilled water, are considered as lost and the exergy of feed water is zero. In this work, the efficiency defined by Eq. (33) is used, since it better reflects the purpose of the desalination process. In the following, the determination of the exergy content of the distilled water is discussed.

The specific exergy of a multi-component flow with $n$ constituents can be calculated from [34]:

$\dot{\mathrm{Ex}}=\dot{m}\left[\left(h-h_{\mathrm{RDS}}\right)-T_{0}\left(s-s_{\mathrm{RDS}}\right)+\sum_{i=1}^{n} \frac{w_{i}}{M_{i}}\left(\mu_{i, \mathrm{RDS}}-\mu_{i, \mathrm{TDS}}\right)\right]$ 
where $h$ is the specific enthalpy, $s$ is the specific entropy, and $\mu_{i}, w_{i}$ and $M_{i}$ represent the chemical potential, mass fraction and molar mass of component $i$ in the mixture, respectively. Subscript RDS and TDS in the above equation refer to the restricted dead state and total dead state, respectively. At the restricted dead state, the temperature and pressure of the flow are at equilibrium with the environment, while the flow composition is kept unchanged. At the total dead state, in addition to the temperature and pressure, the composition of the system is also brought to equilibrium with the environment.

Atmospheric pressure at sea level and a temperature of $25^{\circ} \mathrm{C}$ are widely used as the restricted dead state. The definition of the chemical composition of the total dead state is not as straightforward. In seawater desalination systems, usually, the seawater salinity of $35 \mathrm{~g} / \mathrm{kg}$ is considered as the composition of the total dead state. For desalination systems where the input saline water is at different salinities, it is reasonable to consider the chemical composition of the available feed stream as the chemical composition of the environment. Such a choice of TDS composition ensures that any process that results in two streams of water, with relatively higher and relatively lower concentrations with respect to the feed water, will entail an increase in the exergy of both produced streams, and hence will consume work. It is noted that the sum of the first two terms in the right-hand side of Eq. (34) represents the physical exergy and the last term shows the chemical exergy.

The easiest way to calculate the chemical exergy is by assuming the saline water as an ideal solution of sodium chloride and water. The ideal solution assumption implies that the intermolecular forces are equal between all components of the solution $\left(\mathrm{Na}^{+}-\mathrm{H}_{2} \mathrm{O}, \mathrm{Cl}^{-}-\mathrm{H}_{2} \mathrm{O}\right.$, and $\left.\mathrm{H}_{2} \mathrm{O}-\mathrm{H}_{2} \mathrm{O}\right)$. Therefore, there is no change of enthalpy upon replacing the bonds between some water molecules with ion-water bonds. It can be shown that for such an ideal solution, the exergy of pure water at the dead state temperature and pressure ( $T_{0}$ and $P_{0}$ ) with respect to the feed water as the total dead state is [35]:

$\dot{\mathrm{Ex}} \mathrm{ch}, d_{d}=-\dot{m}_{d} \frac{R_{u} T_{0}}{M_{\mathrm{H}_{2} \mathrm{O}}} \ln x_{w, f, \mathrm{dis}}$

where $x_{w, f \text {,dis }}$ is the dissociated mole fraction of the water in the saline feed water. For $\mathrm{NaCl}$-water solution $x_{w w, \text { dis }}=$ $n_{w} /\left(n_{w}+2 n_{s}\right)$, where $n_{w}$ and $n_{s}$ are the number of moles of water and $\mathrm{NaCl}$ in the solution, and the factor 2 in the denominator is to account for breaking of each $\mathrm{NaCl}$ molecule into 2 ions (dissociation). For small salinities, Eq. (35) can be further simplified by using Taylor expansion of the logarithmic term and replacing the water mole fraction with the salt mole fraction from $x_{s, f \text { dis }}=1-x_{w, f, \text { dis' }}$ to yield $\dot{E x}_{\mathrm{ch}, d}=\dot{m}_{d} R_{u} T_{0} x_{s, f, \text { dis }} / M_{\mathrm{H}_{2} \mathrm{O}}$ . Having the salinity, $S$ (in ppt), the dissociated water mole fraction in Eq. (35) can be calculated as $x_{w f, d i s}=(1,000-S) /$ $\left(1,000-S+2 S M_{\mathrm{H}_{2} \mathrm{O}} / M_{s}\right)$. The exergy of the distilled water can be approximated by replacing Eq. (35) into Eq. (34). It is noted that more accurate expressions for the chemical exergy of water mixtures can be derived by accounting for the non-ideality of the solution [36].
An alternative approach to the calculation of the exergy of the distilled water is using the tabulated values for enthalpy, entropy and chemical potential of saline water directly in Eq. (34). Such tabulated properties have been compiled for seawater and are available for a wide range of practical temperatures, pressures and salinities $[23,30]$. The available correlations in these databases allow for calculation of exergy at various total dead state temperatures, pressures and salinities. In this work, the exergy efficiencies are calculated using the actual exergy values of the distilled water.

\section{Results and discussion}

The developed model was employed to analyze the performance of the MVCD system under various operating conditions. The performance results, including distillation rate, input heat requirements, and energy and exergy performance metrics are presented and discussed. The effect of the hot-end temperature, number of effects, and salinity of the feed water on the energy and exergy performance of the desalination system were investigated. The number of effects was varied from 2 to 14 . A constant inlet water temperature of $25^{\circ} \mathrm{C}$ and hot-end temperatures from $50^{\circ} \mathrm{C}$ to $90^{\circ} \mathrm{C}$ were considered. Cooling water with a mass flow rate of $0.12 \mathrm{~kg} / \mathrm{s}$ flowed through the condenser. Thermal analysis of the condenser showed an overall thermal resistance of $R_{\text {cond }, \varepsilon-\mathrm{NTU}}=5.3 \times 10^{-4}{ }^{\circ} \mathrm{C} / \mathrm{W}$. The inlet mass flow rate of feed water to each vapor chamber was equal to $0.008 \mathrm{~kg} / \mathrm{s}$. The deaerator outlet temperature was set to $95^{\circ} \mathrm{C}$ and the related heat exchanger had an effectiveness of 0.95 .

\subsection{Non-condensable gas effect}

First, the effect of the accumulation of the non-condensable gasses on the performance of the MVCD system was studied. A base-case MVCD system with six effects, a hot-end temperature of $70^{\circ} \mathrm{C}$, feed water salinity of $35 \mathrm{ppt}$, and no heat recovery from the discharged fluids was considered. Fig. 3a shows the evolution of the air volume fraction profile inside the first effect. The horizontal axis shows the distance from the heated wall, with $x / \mathrm{L}=0$ and $x / \mathrm{L}=1$ being the heated and cooled walls, respectively. As evident, the air has significantly greater mole fraction in the vicinity of the cold wall. The air mole fraction at the cold wall is inversely proportional to the saturation pressure of the vapor. Fig. $3 \mathrm{~b}$ shows the decrease of the GOR with increasing the operation time. The presence of air in the feed water affects the GOR in two ways; (i) the partial air removal from the feed water in the deaerator unit requires heat that lowers the overall GOR and (ii) the mass resistance induced by the accumulated air within the effects decreases the partial pressure of the vapor and creates additional temperature drops that eventually lead to smaller distillate production rates. Whereas the amount of the heat consumed by the deaerator unit does not change significantly with the operation time, the accumulated air within the effects increases linearly with time. For the results shown in Fig. 3, the deaerator heat was about $7 \%$ of the heat input to the first effect $(\sim 550 \mathrm{~W}$ deaerator heat vs. 7,900 W heat input to the first effect) 

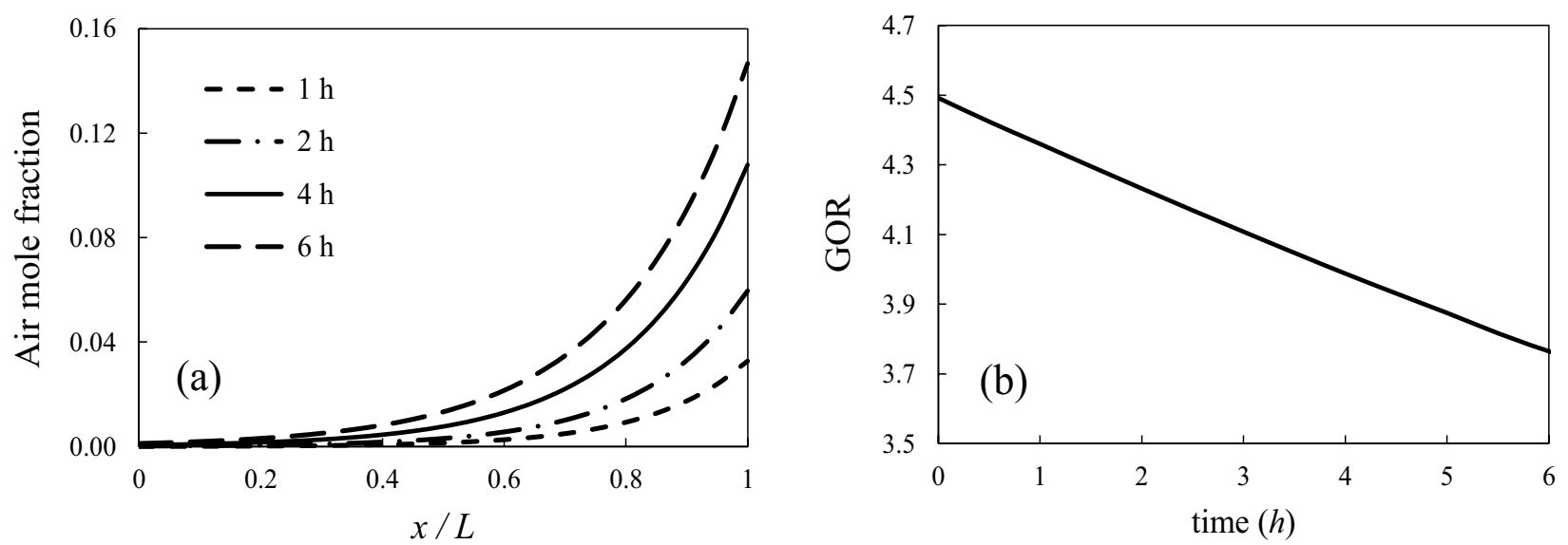

Fig. 3. (a) Evolution of the air mole fraction distribution throughout the first effect and (b) the effect of non-condensable gasses on the temporal variations of the GOR, for a MVCD with six effects, hot-end temperature of $70^{\circ} \mathrm{C}$, feed water salinity of $35 \mathrm{ppt}$, and no heat recovery from the discharged fluids.

The average GOR during an operation time $t$ can be obtained by averaging the GOR over that time interval. It was assumed that the degassing procedure was necessary when the average GOR dropped by $5 \%$. The results depicted in Fig. $3 \mathrm{~b}$ show that after $3 \mathrm{~h}$ of continuous operation the GOR dropped to about $90 \%$ of its initial value $(4.1$ at $t=3 \mathrm{~h}$ compared to 4.5 at $t=0$ ). Thus, the average GOR during the first $3 \mathrm{~h}$ of continuous operation was about $95 \%$ of the initial value. As such, performing the degassing procedure after $3 \mathrm{~h}$ of continuous operation limits the performance degradation due to the presence of non-condensable gasses to about $5 \%$. The following results are based on the assumption that the degassing procedure was performed at the proper time to maintain an average GOR of $95 \%$ of the initial value. This allows to neglect the effect of the presence of non-condensable gasses within the system. However, the heat consumption by the deaerator unit had to be accounted for regardless of the operation time.

\subsection{Model validation}

In the absence of desalination systems with an exactly similar design to the MVCD system, a parallel-feed MED system was used for comparison due to its fundamental resemblance to the present design. To this end, the performance of the MVCD system in terms of GOR and specific surface area (total heat transfer surface area of the system divided by the pure water production rate) was compared with a commercial-scale MED system studied by El-Dessouky and Ettouney [37]. For this comparison, the number of effects, the hot-end temperature, salinity and temperature of the feed water, specific flow rate and temperature rise of the cooling water, and the recovery ratio were set to the reported values in [37] (Table 2, Section 4.3.4), and the GOR and the specific heat transfer area were compared for the two systems. The operating and design conditions, as well as the GOR and specific heat transfer areas, are shown in Table 1. It is noted that all the parameters used for this comparison are independent of the actual system size. As seen in this table, the GOR and the specific heat transfer area of the MVCD system are comparable with the parallel feed MED system despite the small-scale of the MVCD.

\subsection{Parametric studies with and without heat recovery from the discharged fluids}

The base-case MVCD system introduced earlier in this section was employed as a benchmark to assess the effects of the hot-end temperature, the number of effects and the salinity of the feed water on the performance metrics of the MVCD system. The design and operating conditions of the base-case system are shown in Table 2:

Fig. $4 a$ shows the vapor pressure and temperature across the MVCD system. As expected, the vapor pressure and temperature were greater in the upstream effects (i.e. vapor chambers closer to the hot-end) with an average temperature difference of about $4.6^{\circ} \mathrm{C}$ between neighboring effects. It is noted that the base-case MVCD system was not meant to be the optimal system and the temperature drops can be decreased by either increasing the number of effects or decreasing the hot-end temperature. The input heat and distillation rate in each effect are shown in Fig. 4b. The input heat consists of a sensible heat portion and a latent heat portion that is transferred to the next effect. Both the latent heat and sensible heat decreased in the downstream effects. The decrease of the latent heat transfer to the downstream effects was due to the subtraction of the sensible heat. The decrease of sensible heat was due to the smaller saturation temperature in the downstream effects which decreased the required sensible heating. Consistent with the decreasing latent heat transfer, the distilled water production rate also decreased in the downstream effects.

The four major thermal resistances in each chamber are shown in Fig. 5. The greatest thermal resistance was due to the heat transfer through the evaporating liquid film, followed by heat transfer through the condensing liquid film, conduction across the solid walls, and finally the thermal resistance due to the saturation temperature drop between the evaporator and condenser sides of each chamber. It is noted that the resistance due to the boiling 
Table 1

Comparison of the GOR and specific heat transfer area of the MVCD system with and without heat recovery from discharged fluids with a parallel feed MED system reported in [37]

\begin{tabular}{llll}
\hline & $\begin{array}{l}\text { Parallel } \\
\text { feed } \\
\text { MED }\end{array}$ & $\begin{array}{l}\text { MVCD without } \\
\text { heat recovery from } \\
\text { discharged fluids }\end{array}$ & $\begin{array}{l}\text { MVCD with heat } \\
\text { recovery from } \\
\text { discharged fluids }\end{array}$ \\
\hline Number of effects & 8 & 8 & 8 \\
Heat source temperature & $90^{\circ} \mathrm{C}$ & $90^{\circ} \mathrm{C}$ & $90^{\circ} \mathrm{C}$ \\
Salinity of the input water $(\mathrm{ppt})$ & 42 & 42 & 42 \\
Recovery ratio & 0.325 & 0.325 & 0.325 \\
Specific flow rate of cooling water $\left(\dot{m}_{\mathrm{cw}} / \dot{m}_{d}\right)$ & 8.9 & 8.9 & 8.9 \\
Specific heat transfer area $\left(\mathrm{m}^{2} /(\mathrm{kg} / \mathrm{s})\right)$ & 335 & 301 & 302 \\
GOR & 4.9 & 4.4 & 5.2 \\
\hline
\end{tabular}

Table 2

Design and operating parameters of the base-case MVCD system

\begin{tabular}{lll}
\hline & $\begin{array}{l}\text { Base-case MVCD } \\
\text { without heat recovery } \\
\text { from discharged fluids }\end{array}$ & $\begin{array}{l}\text { Base-case MVCD with } \\
\text { heat recovery from } \\
\text { discharged fluids }\end{array}$ \\
\hline Number of effects & 6 & 6 \\
Heat source temperature & $70^{\circ} \mathrm{C}$ & $70^{\circ} \mathrm{C}$ \\
Salinity of the input water $(\mathrm{ppt})$ & 35 & 35 \\
Temperature of the cooling water & $25^{\circ} \mathrm{C}$ & $25^{\circ} \mathrm{C}$ \\
Specific flow rate of cooling water $\left(\dot{m}_{\mathrm{cw}} / \dot{m}_{d}\right)$ & 6.9 & 7.0 \\
Recovery ratio & 0.36 & 0.36 \\
Specific heat transfer area $\left(\mathrm{m}^{2} /(\mathrm{kg} / \mathrm{s})\right)$ & 420 & 424 \\
Input heat transfer rate $(\mathrm{kW})$ & 9.4 & 8.5 \\
GOR & 4.5 & 5.0 \\
\hline
\end{tabular}
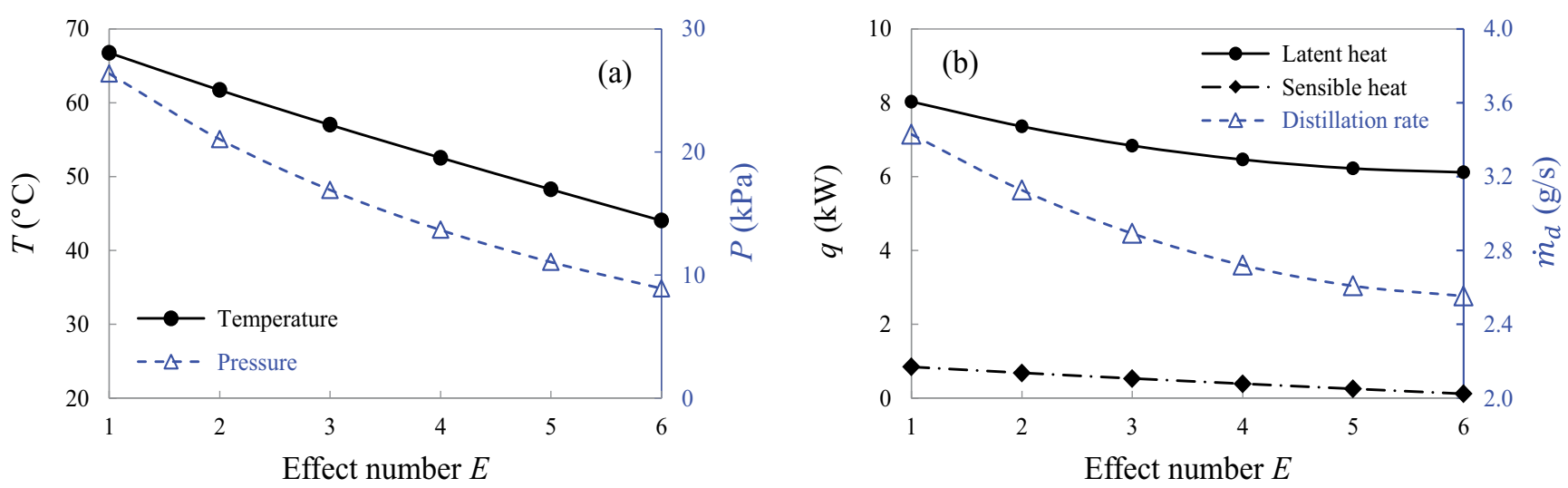

Fig. 4. (a) Distribution of the vapor saturation temperature and pressure and (b) latent and sensible heat transport, in each of the effects of the base-case MVCD system.

point elevation in each effect was obtained by dividing the corresponding temperature drop by the thermal energy transferred across the effect. This resistance imposes a constraint on the theoretical efficiency of thermal desalination technologies [5].

The greater thermal resistance of the evaporating liquid film compared to the condensing liquid film can be attributed to its greater thickness. In each effect, the non-evaporated portion of the feed water added to the thickness, and thermal resistance, of the evaporating liquid film compared to the condensing liquid film. Also, it is observed in Fig. 5 that the thermal resistances of the evaporating liquid film increased in the downstream effects. This was found to be mainly due to the increased water viscosity at lower 
temperatures, as well as the smaller rate of evaporation in the downstream effects which led to increased film thickness. Quantitatively, the viscosity of water in the evaporating liquid film increased from $0.48 \mathrm{mPa} \mathrm{s}$ in the first effect to $0.68 \mathrm{mPa} \mathrm{s}$ in the last effect, showing an increase of $42 \%$. For the condensing liquid films, the effect of the increased viscosity on increasing the film thickness in downstream effects was balanced by smaller condensation rate. Thus, the condensing liquid film thickness and its thermal resistance remained fairly constant across the system. Inspection of the flow regime of the liquid films throughout the system revealed that for the base-case system the evaporating liquid film in all the effects was in the wavy-laminar regime, and the condensing films were laminar, except in the first effect which was flowing under the wavy-laminar regime.

The resistances has shown in Fig. 5 can be used to calculate an overall heat transfer coefficient for each effect; $U_{n}=1 /\left(R_{n} A_{n}\right)$, where $A_{n}$ and $R_{n}$ are the cross-sectional surface area $(W \times H)$ and the sum of the thermal resistances of effect $n$, respectively. The overall heat transfer coefficients were found to be from $3.0 \mathrm{~kW} / \mathrm{m}^{2 \circ} \mathrm{C}$ for the first effect to

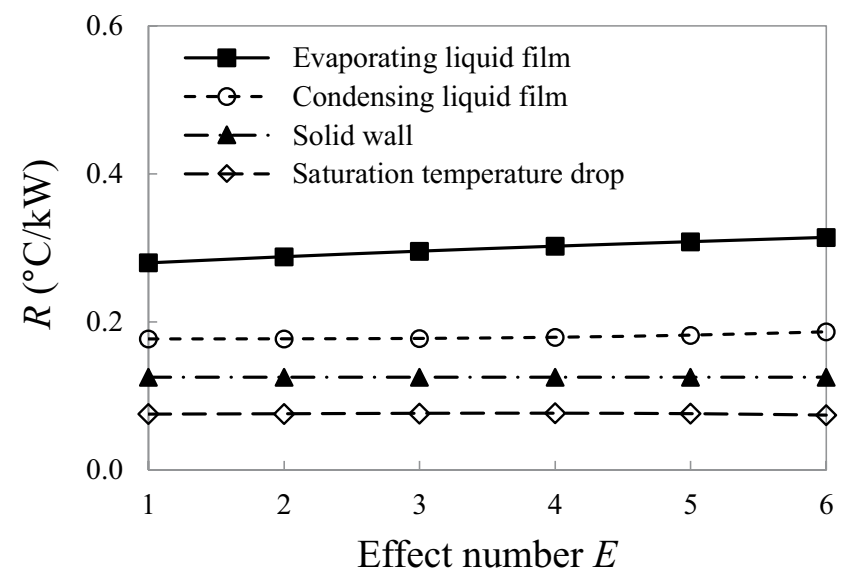

Fig. 5. Major thermal resistances of each of the effects of the basecase MVCD system.

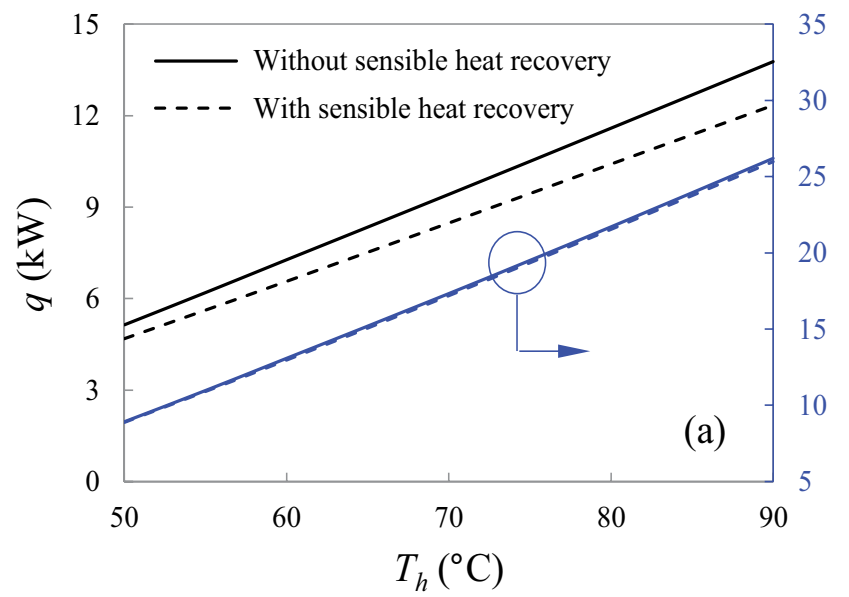

$2.8 \mathrm{~kW} / \mathrm{m}^{2 \circ} \mathrm{C} \times$ for the last effect. These numbers are consistent with reported data in the literature for large-scale MED systems [32,37].

Fig. 6 shows the effect of the hot-end temperatures from $50^{\circ} \mathrm{C}$ to $90^{\circ} \mathrm{C}$ on the input heat requirement and total distillate production rate, as well as the recovery ratio of the MVCD system, with and without heat recovery from the discharging brine and distillate. The number of effects and the salinity of the input water remained constant for all cases. As shown in Fig. 6a, there was an almost linear relation between increasing the hot-end temperature and the increase of both the heat input and the distillate production rate. Quantitatively, increasing the hot-end temperature from $50^{\circ} \mathrm{C}$ to $90^{\circ} \mathrm{C}$ resulted in more than 2 times an increase in both the heat input and distillate production rate. Also, it is evident in this figure that heat recovery from the discharging brine and distillate decreased the input heat requirement by more than $10 \%$ without noticeable loss in distilled water production. The decrease in the input heat requirement was due to the smaller need for sensible heating of the feed water inside the chambers to bring it to the saturation state. The effect of the hot-end temperature on the recovery ratio is shown in Fig. $6 \mathrm{~b}$. The recovery ratio increased almost linearly with increasing the hot-end temperature. Considering the fixed feed water flow rate, the increase of the recovery ratio with the temperature is consistent with the increased distillation rates shown in Fig. 6a.

The effect of the hot-end temperature on the first and second law performance metrics (GOR and $\eta_{\mathrm{II}, 2}$ ), with and without heat recovery from discharging streams, is shown in Fig. 7 for a constant number of effects and input water conditions. Consistent with the results shown in Fig. 6, an almost linear relation between the GOR and the hot-end temperature was observed. On the other hand, the second law efficiency decreased with increasing the hot-end temperature. As shown in Eq. (33), the exergy efficiency increases by increasing the distillate production rate and decreases by increasing the input thermal exergy. Both the input exergy and useful output exergy (exergy of the distillate flow stream, $\dot{m}_{d} \mathrm{ex}_{d}$ ), increased by increasing the hot-end temperature. However, the decreasing trend of the exergy efficiency

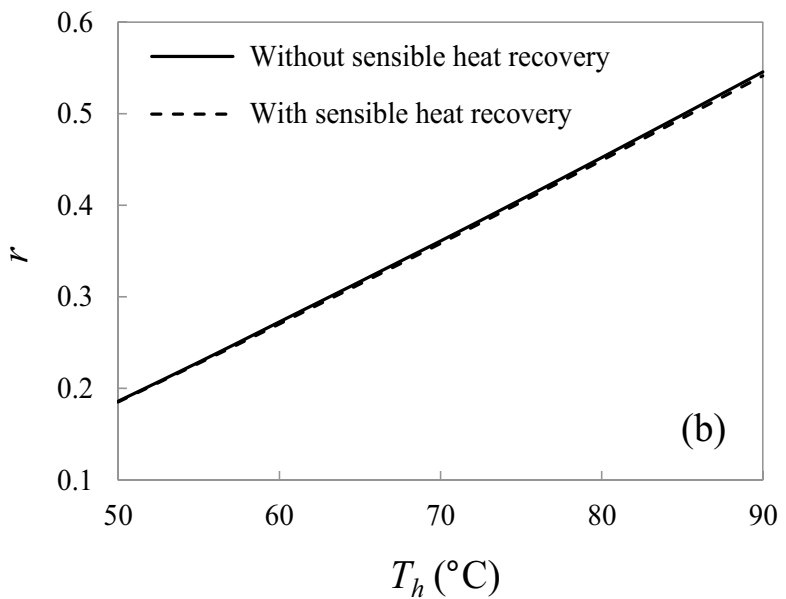

Fig. 6. Effect of the hot-end temperature on (a) the input heat and distillation rate and (b) the recovery ratio of the base-case MVCD, with and without heat recovery from discharging fluids. 


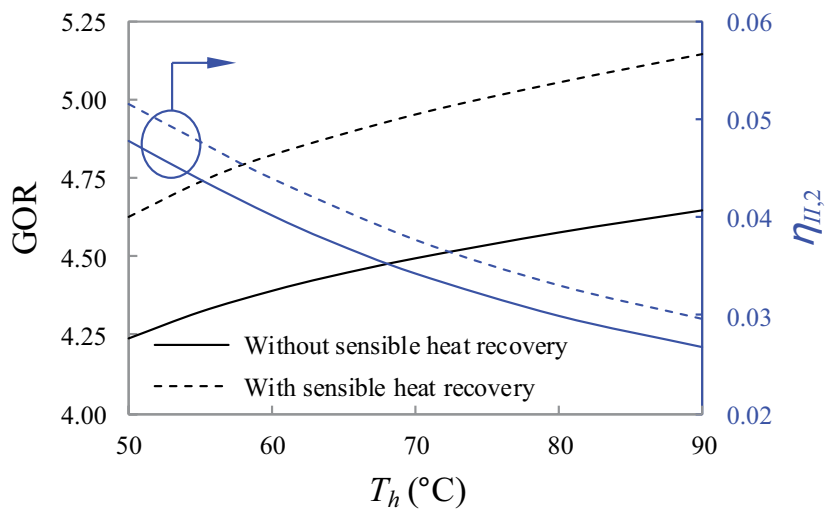

Fig. 7. Effect of the hot-end temperature on the gained output ratio and second law efficiency of the base-case MVCD, with and without heat recovery from the discharging fluids.

in Fig. 7 suggests that the effect of the increased exergy of the input thermal energy overweighed the greater exergy of the distilled water. Both GOR and second law efficiency benefited from heat recovery from discharging streams. The improved energy and exergy performance was due to the smaller input heat requirements for almost the same distillation rate.

Fig. 8 shows the effect of the number of vapor chambers on the heat input, distillation rate and recovery ratio of the MVCD system, while the hot-end temperature and input water conditions were kept constant. Many effects from 2 to 14 were investigated for a hot-end temperature of $70^{\circ} \mathrm{C}$ and feed water mass flow rate of $8 \mathrm{~g} / \mathrm{s}$ per chamber and salinity of 35 ppt. As shown in Fig. 8a, the heat input first decreased with increasing the number of effects and later increased (flattened) for the MVCD without (with) heat recovery from discharged fluids. On the other hand, the distillate production rate increased monotonically by increasing the number of vapor chambers. The heat input requirement of the MVCD system has two components, the heat consumed by the deaerator and the heat input to the first effect. In general, increasing the number of vapor chambers decreases the heat input to the first effect due to the increased overall

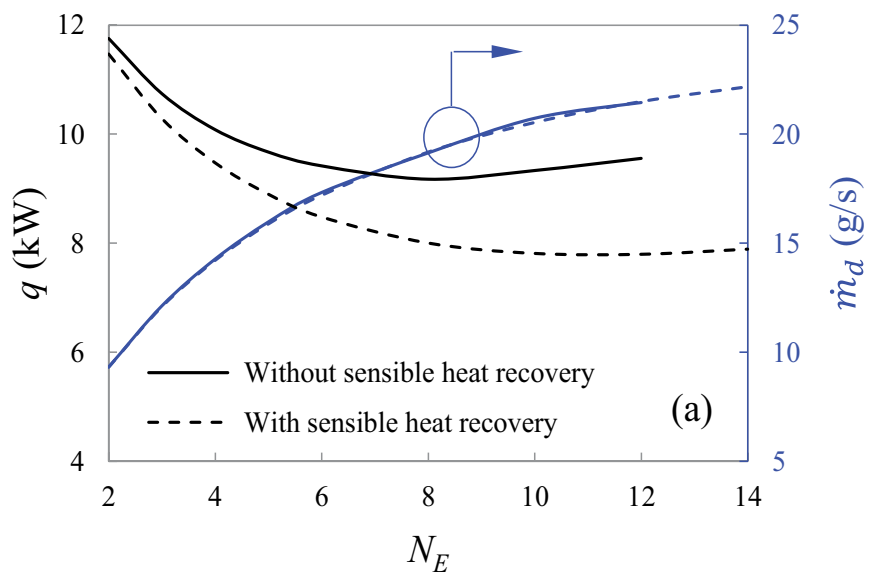

thermal resistance of the system. For fixed hot- and cold-end temperatures, increasing the thermal resistance results in smaller heat throughput. On the other hand, the heat consumption of the deaerator increases by increasing the number of effects, due to the greater feed water mass flow rate. As shown in Fig. 8a, as the number of effects increased, the greater heat consumption by the deaerator overweighed (balanced) the smaller heat input to the first effect for the MVCD systems without (with) heat recovery. The smaller heat throughput implies smaller distillate production rate in each vapor chamber. However, the increased number of vapor chambers more than offset the reduced distillation rate in individual effects. The maximum number of chambers in a system without sensible heat recovery was 12 . Further increase in the number of effects in this case resulted in decreased condensation temperatures in the last effect to an extent where the heat transfer rate to the condenser was not sufficient to balance the heat output from the last effect. As evident in Fig. 8a, heat recovery from discharging fluids decreased the input heat requirements with no noticeable effect on the distilled water production rate. The positive effect of heat recovery was more profound for greater number of effects since the amount of discharged fluids, and the thermal energy recovered from them, increased by increasing the number of effects.

Fig. $8 \mathrm{~b}$ shows the effect of the number of vapor chambers on the recovery ratio. The recovery ratio decreased from $54 \%$ to $19 \%$ by increasing the number of effects from 2 to 14 for the case with sensible heat recovery. It should be noted that the total input feed water also increased with increasing the number of effects. Thus, despite the smaller recovery ratio for greater number of effects, the total distillation rate was greater for MVCD systems with greater number of effects (Fig. 8a).

Variations of the GOR and second law efficiency with the number of effects are shown in Fig. 9 for constant hot-end temperature and input water conditions. As evident, both second law efficiency and GOR first increased by increasing the number of effects in the MVCD system and then reached a plateau. This trend is consistent with the variations of the heat input and distillation rate shown in Fig. 8a. Overall, MVCD systems with a greater number of effects were

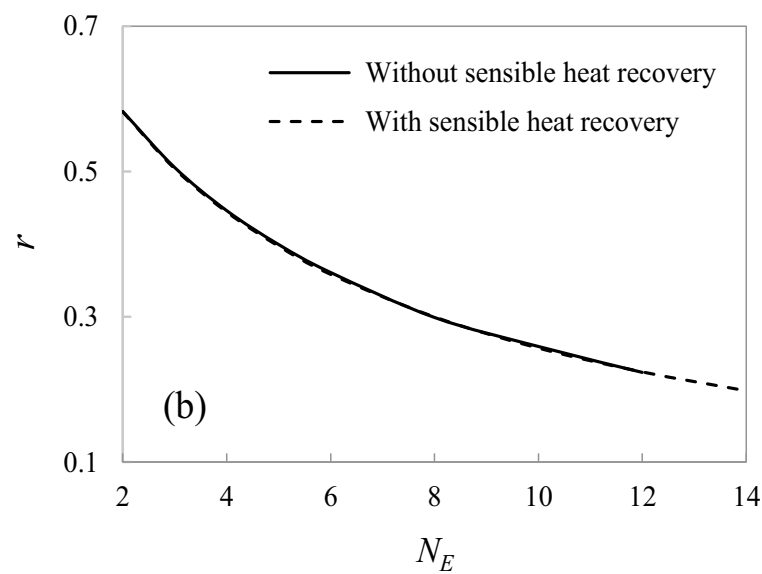

Fig. 8. (a) Variation of the input heat and distillation rate and (b) the recovery ratio, with the number of effects of MVCD systems at a hot end-temperature of $70^{\circ} \mathrm{C}$, with and without heat recovery from the discharging fluids. 


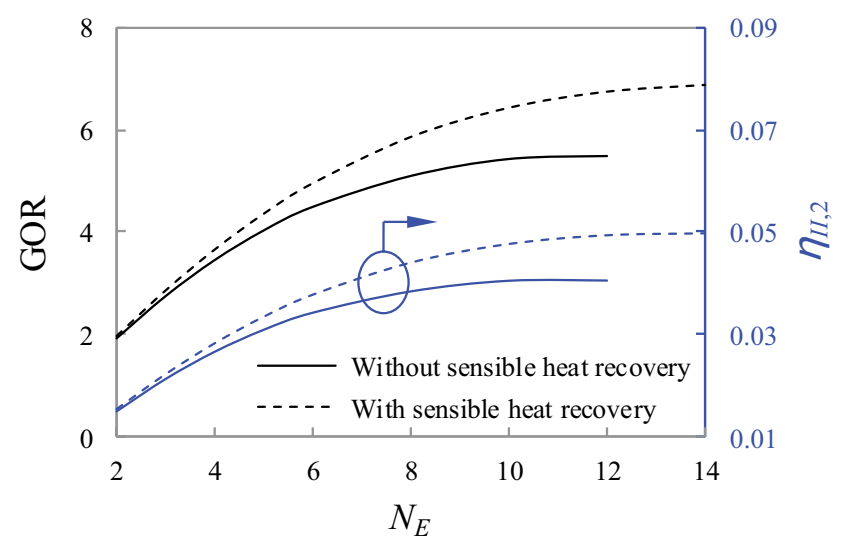

Fig. 9. Variation of the gained output ratio and the second law efficiency with the number of effects of MVCD systems at a hot end-temperature of $70^{\circ} \mathrm{C}$, with and without heat recovery from the discharging fluids.

more efficient from both energy and exergy points of view. Nevertheless, it should be noted that the improved efficiency comes with a higher price associated with higher material and manufacturing costs [38]. As expected, energy recovery from the discharging fluids increased both GOR and $\eta_{\mathrm{II}, 2}$. The improvement was more profound for MVCD systems with greater number of effects, mainly due to the greater amount of discharging fluids and their greater thermal energy available for recovery.

Fig. 10 shows the effect of input water salinity on heat transfer rate and distillate production for the base-case MVCD system, with and without heat recovery from discharging fluids. The number of effects, the hot-end temperature and the temperature of the input water were kept constant. For all cases, the input water was considered to be at the total dead state, that is, its chemical (and mechanical) exergy was zero. As evident in Fig. 10a, both the input heat and distillation rate decreased by increasing the input water salinity, indicating greater overall thermal resistance at higher salinities. In particular, the boiling point elevation profoundly increased by increasing salinity. Quantitatively,

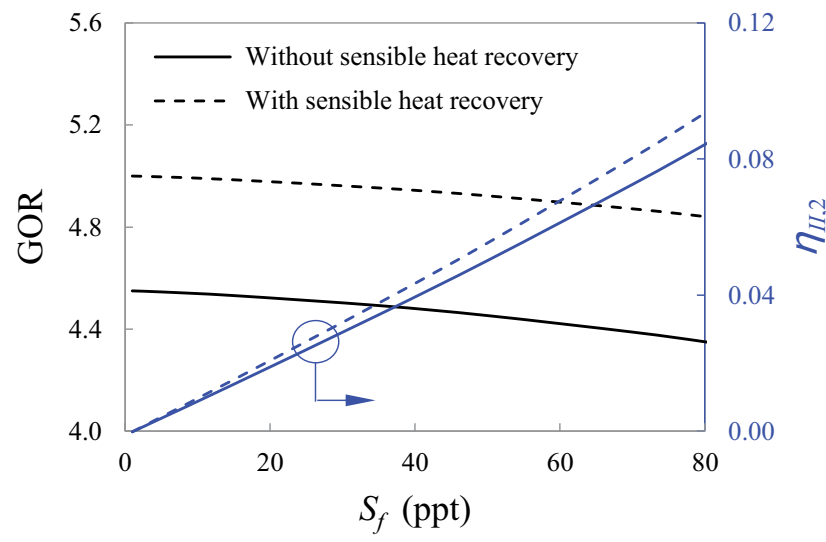

Fig. 11. Effect of the feed water salinity on the gained output ratio and the second law efficiency of the base-case MVCD system, with and without heat recovery from the discharging fluids.

doubling the feed water salinity from 35 to 70 ppt increased the boiling point elevation by about $120 \%$, and decreased the input heat requirement and distillation rate by about $8 \%$ and $10 \%$, respectively. Consistent with previous results, heat recovery from discharging fluids decreased the input heat requirement by about $10 \%$ with small effect on the distillation rate. The recovery ratio vs. the feed water salinity is shown in Fig. 10b. Doubling the feed water salinity from 35 to 70 ppt decreased the recovery ratio by about $10 \%$.

The effect of feed water salinity on the performance metrics is shown in Fig. 11 for a fixed number of effects, hot-end temperature and input water temperature. The GOR decreased and the second law efficiency increased by increasing the salinity. Even though both the input heat and distillation rate decreased by increasing the salinity, it can be inferred from the decreasing trend of GOR that the latter had a more prevalent effect, leading to an overall decrease in GOR. The increase of the second law efficiency was due to the relatively greater chemical exergy of distilled water at higher feed water salinities; as the salinity associated with the total dead state increases, more work is needed to separate pure water from the solution. Once again, the positive
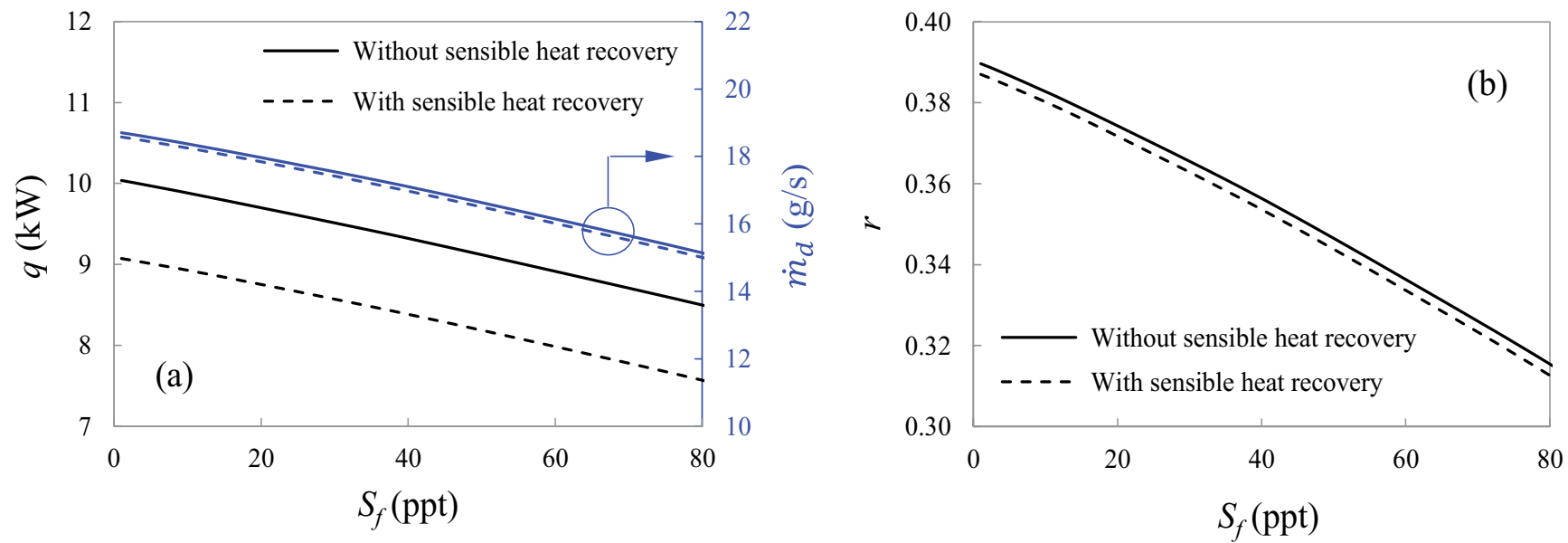

Fig. 10. Effect of the feed water salinity on (a) the input heat and distillation rate and (b) recovery ratio of the base-case MVCD system, with and without heat recovery from the discharging fluids. 
effect of heat recovery from the discharging fluids on the improvement of GOR and second law efficiency is observed in Fig. 11.

\section{Conclusions}

The energy and exergy analyses of a novel MVCD system was presented. The advantages of the present design include modularity, portability, use of any heat source directly with no need to conversion to steam, and a short vapor transport path compared to conventional MED systems. A heat and mass transfer model was developed to quantify the heat transfer and distilled water production rates. The effects of the hot-end temperature, number of vapor chambers, and salinity of the feed water on the energy and exergy performance of the system were studied. The appropriate forms of energy and exergy performance metrics were determined. The system performance was compared with a large-scale parallel feed MED system for identical operating conditions. It was found that the MVCD system presents comparable GOR and specific heat transfer area despite the small-scale. The mass transfer analysis showed that the MVCD system must be degassed after about $3 \mathrm{~h}$ of operation to maintain an average GOR of $95 \%$ of the gas-free system. For all the cases, the greatest temperature drops were found to be associated with heat transfer across the evaporating liquid film, followed by temperature drops due to heat transfer across the condensing liquid film, conduction through the solid walls and boiling point elevation. Increasing the hotend temperature and/or the number of effects improved the GOR, with the latter having a much more profound effect. The second law efficiency increased by decreasing (increasing) the hot-end temperature (the number of effects). The increasing trend of the GOR and second law efficiency with increasing the number of effects lessened at greater number of effects due to the increased heat requirement of the deaerator. Increasing the feed water salinity decreased the GOR and increased the second law efficiency. The effect of the heat recovery from the discharging brine and distilled water streams on the performance of the MVCD system was also investigated and was found to decrease the input heat requirement by about $10 \%$ with no significant effect on the distillation rate. The heat transfer and thermodynamic analysis presented in this work established the technical feasibility of the MVCD system. Further study is needed to establish the economic viability of the presented system through a comprehensive thermo-economic analysis.

\section{Acknowledgements}

Support from the Advanced Research Projects AgencyEnergy under Award Number DE-AR0001069 is acknowledged and appreciated. Support from the Gallogly College of Engineering at the University of Oklahoma is also appreciated.

\section{Symbols}

$A \quad-\quad$ Surface area, $\mathrm{m}^{2}$

E - Effect/stage number

Ex - Exergy, J

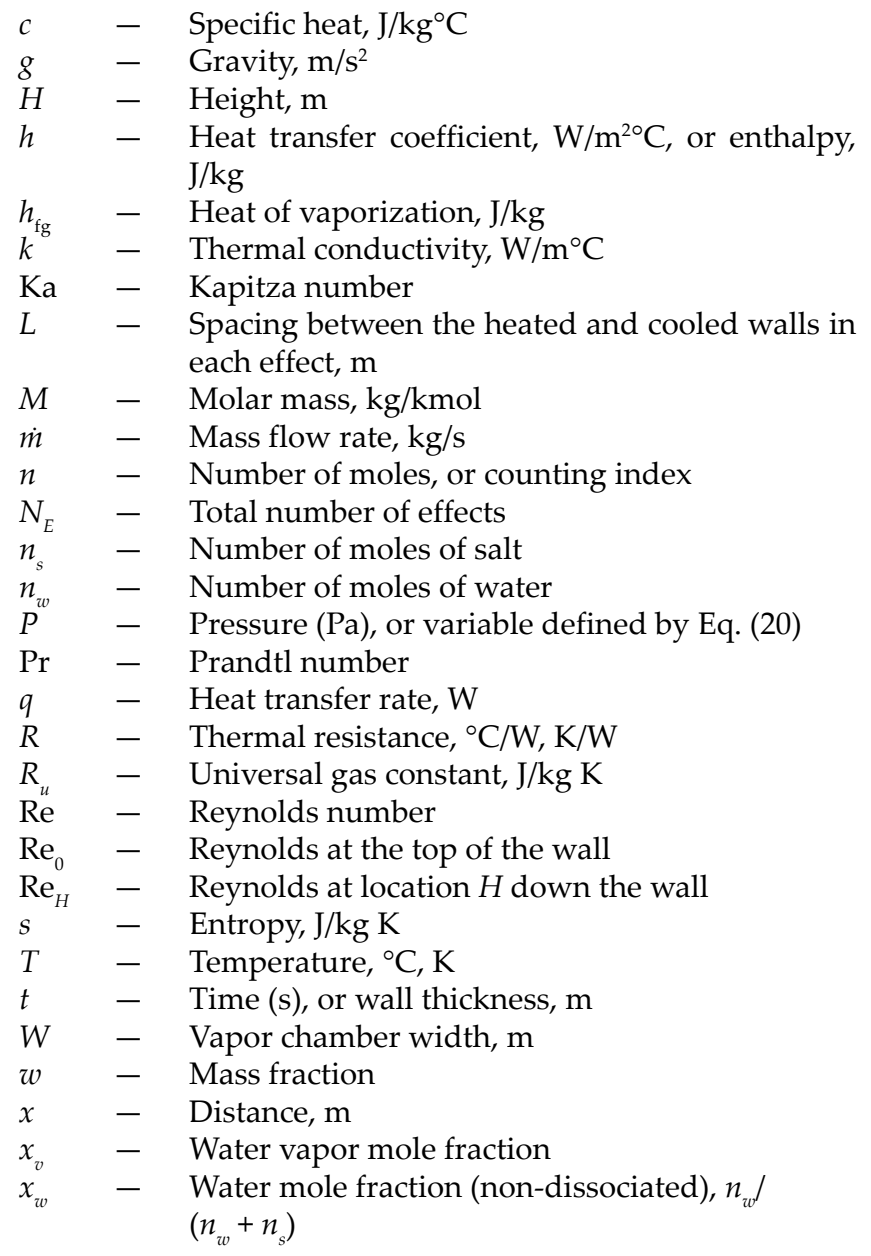

\section{Greek}

$\Gamma \quad-$

Liquid mass flow rate per unit width, $\mathrm{kg} / \mathrm{m} \mathrm{s}$

$\eta_{\mathrm{II}} \quad-\quad$ Second law efficiency

$v \quad-\quad$ Kinematic viscosity

$\mu \quad-\quad$ Dynamic viscosity (Pa s), or chemical potential per mole, $\mathrm{J} / \mathrm{mol}$

$\rho \quad-\quad$ Density, $\mathrm{kg} / \mathrm{m}^{3}$

$\sigma \quad-\quad$ Surface tension, $\mathrm{N} / \mathrm{m}$

\section{Subscripts}

$\begin{array}{lll}0 & - & \text { At dead state } \\ b & - & \text { Brine } \\ \text { bpe } & - & \text { Boiling point elevation } \\ \text { ch } & - & \text { Chemical } \\ \text { cond } & - & \text { Related to condensing side of the wall } \\ \text { conv } & - & \text { Convective } \\ \text { cw } & - & \text { Cooling water } \\ d & - & \text { Distilled water } \\ \text { des } & - & \text { Destroyed } \\ \text { dis } & - & \text { Related to dissociated mole fraction } \\ \text { evap } & - & \text { Related to evaporating side of the wall } \\ f & - & \text { Feed water } \\ \text { fc } & - & \text { Related to condensing liquid film } \\ \text { fe } & - & \text { Related to evaporating liquid film }\end{array}$




$\begin{array}{lll}h & - & \text { Hot } \\ l & - & \text { Liquid } \\ \text { RDS } & - & \text { At restricted dead state } \\ s & - & \text { Salt, } \\ \text { sat } & - & \text { Saturation } \\ \text { TDS } & - & \text { At total dead state } \\ \text { th } & - & \text { Thermal } \\ v & - & \text { Vapor } \\ w & - & \text { Solid wall }\end{array}$

\section{References}

[1] Organisation for Economic Co-operation and Development, OECD Environmental Outlook to 2050: The Consequences of Inaction, Paris, 2012.

[2] G. Amy, N. Ghaffour, Z.Y. Li, L. Francis, R.V. Linares, T. Missimer, S. Lattemann, Membrane-based seawater desalination: present and future prospects, Desalination, 401 (2017) 16-21.

[3] Y. Xue, X.Z. Du, Z.H. Ge, L.J. Yang, Study on multi-effect distillation of seawater with low-grade heat utilization of thermal power generating unit, Appl. Therm. Eng., 141 (2018) 589-599.

[4] C. Frantz, B. Seifert, Thermal analysis of a multi effect distillation plant powered by a solar tower plant, Energy Procedia, 69 (2015) 1928-1937.

[5] D. Brogioli, F. La Mantia, Y.Y. Yip, Thermodynamic analysis and energy efficiency of thermal desalination processes, Desalination, 428 (2018) 29-39.

[6] I.S. Al-Mutaz, I. Wazeer, Comparative performance evaluation of conventional multi-effect evaporation desalination processes, Appl. Therm. Eng., 73 (2014) 1194-1203.

[7] H.T. El-Dessouky, H.M. Ettouney, Multiple-effect evaporation desalination systems. thermal analysis, Desalination, 125 (1999) 259-276.

[8] P. Druetta, P. Aguirre, S. Mussati, Optimization of multi-effect evaporation desalination plants, Desalination, 311 (2013) 1-15.

[9] P. Fiorini, E. Sciubba, Modular simulation and thermoeconomic analysis of a multi-effect distillation desalination plant, Energy, 32 (2007) 459-466.

[10] M. Sagharichiha, A. Jafarian, M. Asgari, R. Kouhikamali, Simulation of a forward feed multiple effect desalination plant with vertical tube evaporators, Chem. Eng. Process. Process Intensif., 75 (2014) 110-118.

[11] K.J. Gabriel, P. Linke, M.M. El-Halwagi, Optimization of multi-effect distillation process using a linear enthalpy model, Desalination, 365 (2015) 261-276.

[12] A. Ophir, F. Lokiec, Advanced MED process for most economical sea water desalination, Desalination, 182 (2005) 187-198.

[13] Y.Q. Wang, N. Lior, Thermoeconomic analysis of a low-temperature multi-effect thermal desalination system coupled with an absorption heat pump, Energy, 36 (2011) 3878-3887.

[14] B.B. Saha, I.I. El-Sharkawy, M.W. Shahzad, K. Thu, L. Ang, K.C. $\mathrm{Ng}$, Fundamental and application aspects of adsorption cooling and desalination, Appl. Therm. Eng., 97 (2016) 68-76.

[15] A. Chorak, P. Palenzuela, D.-C. Alarcón-Padilla, A. Ben Abdellah, Experimental characterization of a multi-effect distillation system coupled to a flat plate solar collector field: empirical correlations, Appl. Therm. Eng., 120 (2017) 298-313.

[16] M.M. Morad, H.A.M. El-Maghawry, K.I. Wasfy, A developed solar-powered desalination system for enhancing fresh water productivity, Sol. Energy, 146 (2017) 20-29.

[17] K.M. Bataineh, Multi-effect desalination plant combined with thermal compressor driven by steam generated by solar energy, Desalination, 385 (2016) 39-52.
[18] M.A. Alghoul, P. Poovanaesvaran, M.H. Mohammed, A.M. Fadhil, A.F. Muftah, M.M. Alkilani, K. Sopian, Design and experimental performance of brackish water reverse osmosis desalination unit powered by $2 \mathrm{~kW}$ photovoltaic system, Renewable Energy, 93 (2016) 101-114.

[19] E. Chiavazzo, M. Morciano, F. Viglino, M. Fasano, P. Asinari, Passive solar high-yield seawater desalination by modular and low-cost distillation, Nat. Sustainability, 1 (2018) 763-772.

[20] M.M. Elewa, A.A. El-Shafei, A.A. Moneer, M.M. Naim, Effect of cell hydrodynamics in desalination of saline water by sweeping air pervaporation technique using innovated membrane, Desal. Wat. Treat., 57 (2016) 23293-23307.

[21] V.G. Gude, Emerging Technologies for Sustainable Desalination Handbook, Butterworth-Heinemann, Elsevier, Oxford, United Kingdom, 2018.

[22] S.-S. Hsieh, R.-Y. Lee, J.-C. Shyu, S.-W. Chen, Thermal performance of flat vapor chamber heat spreader, Energy Convers. Manage., 49 (2008) 1774-1784.

[23] K.G. Nayar, M.H. Sharqawy, L.D. Banchik, J.H. Lienhard V, Thermophysical properties of seawater: a review and new correlations that include pressure dependence, Desalination, 390 (2016) 1-24.

[24] A. Faghri, Y. Zhang, Transport Phenomena in Multiphase Systems, Academic Press, Elsevier, Amsterdam, Netherland, 2006.

[25] T.L. Bergman, A.S. Lavine, F.P. Incropera, D.P. DeWitt, Fundamentals of Heat and Mass Transfer, 7th ed., Wiley, Hoboken, 2011.

[26] K.R. Chun, R.A. Seban, Heat transfer to evaporating liquid films, J. Heat Transfer, 93 (1971) 391-396.

[27] K. Stephan, Heat Transfer in Condensation and Boiling, Springer-Verlag, 1992.

[28] W.M. Rohsenow, Heat transfer and temperature distribution in laminar film condensation, J. Heat Transfer, 78 (1956) 1645-1648.

[29] Air Solubility in Water, The Engineering ToolBox, 2004. Available at: https://www.engineeringtoolbox.com/airsolubility-water-d_639.html.

[30] M.H. Sharqawy, J.H. Lienhard V, S.M. Zubair, Thermophysical properties of seawater: a review of existing correlations and data, Desal. Wat. Treat., 16 (2010) 354-380.

[31] K.H. Mistry, R.K. McGovern, G.P. Thiel, E.K. Summers, S.M. Zubair, J.H. Lienhard V, Entropy generation analysis of desalination technologies, Entropy, 13 (2011) 1829-1864.

[32] A. Piacentino, Application of advanced thermodynamics, thermoeconomics and exergy costing to a multiple effect distillation plant: in-depth analysis of cost formation process, Desalination, 371 (2015) 88-103.

[33] K.H. Mistry, J.H. Lienhard V, Generalized least energy of separation for desalination and other chemical separation processes, Entropy, 15 (2013) 2046-2080.

[34] A. Bejan, Advanced Engineering Thermodynamics, John Wiley \& Sons, New York, USA, 2006.

[35] Thermodynamics, Exergy, and Energy Efficiency in Desalination Systems, H.A. Arafat, Ed., Desalination Sustainability: A Technical, Socioeconomic, and Environmental Approach, Elsevier, Amsterdam, Netherlands, 2017.

[36] K.H. Mistry, J.H. Lienhard V, Effect of nonideal solution behavior on desalination of a sodium chloride solution and comparison to seawater, J. Energy Res. Technol., 135 (2013) 042003.

[37] H.T. El-Dessouky, H.M. Ettouney, Fundamentals of Salt Water Desalination, Elsevier, Amsterdam, Netherlands, 2002.

[38] K.H. Mistry, M.A. Antar, J.H. Lienhard V, An improved model for multiple effect distillation, Desal. Wat. Treat., 51 (2013) $807-821$. 